\title{
Fast response integrated MEMS microheaters for ultra low power gas detection
}

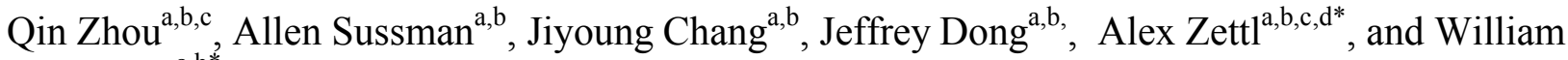 \\ Mickelson $^{\mathrm{a}, \mathrm{b}^{*}}$
}

a Department of Physics, University of California at Berkeley, Berkeley, California 94720, USA

b Center of Integrated Nanomechanical Systems, University of California at Berkeley, Berkeley, California 94720, USA

c Materials Sciences Division, Lawrence Berkeley National Laboratory, Berkeley, California 94720, USA

d Kavli Energy NanoSciences Institute at the University of California, Berkeley and the Lawrence Berkeley National Laboratory, Berkeley, California 94720, USA

Corresponding authors. Tel.: +1 510 642-8358. E-mail address: wmickelson@,berkeley.edu

Corresponding authors. Tel.: +1 510 642-4939. E-mail address: azettl@berkeley.edu

\begin{abstract}
Semiconducting metal oxide (SMO) gas sensors typically operate at a few hundred degrees Celsius and consume hundreds of milliwatts of power, limiting their application in battery-powered devices. An analytical model is presented for the optimization of the heater dimensions, which suggests the minimal power consumption is achieved when heat loss through air conduction and supporting beam conduction are equal. We demonstrate micromachined SMO sensors with optimized microheaters, which consume only $\sim 2 \mathrm{~mW}$ of power when operated continuously at $300{ }^{\circ} \mathrm{C}$. We also measure an ultra-fast thermal response time of $33 \mu \mathrm{s}$ via a transient temperature-resistivity response method. The short response time allows the heaters to be operated in ultra-short pulsing mode decreasing the average power consumption to the $\mu \mathrm{W}$ level. These micromachined SMO sensors are used in proof-of-principle experiments as ultralow power hydrogen sulfide SMO gas sensors.
\end{abstract}

Keywords: gas sensor; low power; semiconducting metal oxide; microheaters; transient temperature response 


\section{Introduction}

Chemical sensors are of vital importance in modern society[1]. Gas detection monitors are employed to ensure that levels of various harmful (e.g. toxic, flammable, etc.) gases are within an acceptable range. These monitors are indispensible in industrial facilities that produce such gases (e.g. oil and natural gas refining), but are also critical for hazardous conditions in residential and other commercial settings. For example, California law (Ca. Health and Safety Code $\S \S 13260$ and $\S \S 17926$ ) requires the installation of carbon monoxide detectors in every household. Of the many technologies used in chemical sensing, semiconducting metal oxide (SMO) sensors offer a robust and low cost solution that can be measured using fairly simple electronic systems. However, conventional SMO sensors usually operate at $300{ }^{\circ} \mathrm{C}$ or higher, requiring hundreds of milliwatts of power consumption per sensor[2]. Employing conventional SMO sensors in battery-operated devices would create an unacceptable drain on stored energy and limit battery lifetime. For example, a typical AA battery of $2000 \mathrm{~mA}$-h only supports 5 hrs of $300 \mathrm{~mW}$ sensor operation. SMO sensors with drastically lower power consumption enables an entirely new marketplace for SMO sensors and other chemical sensors that require elevated operational temperatures, such as pellistors, in applications such as: worker safety, process monitoring, environmental regulation, and personal health monitors (especially for persons with compromised health conditions)[2].

Reducing the size of the SMO sensor is the most effective way to reduce overall power consumption, and this is typically achieved using microhotplates or microheaters[3-25]. We have previously reported a $\mathrm{WO}_{3}$ nanoparticle-based hydrogen sulfide $\left(\mathrm{H}_{2} \mathrm{~S}\right)$ gas sensor based on commercial microheater devices (Kebaili Corporation, KMHP-100)[26]. Microheaters require less space and power than conventional SMO heaters, but also have a significantly shorter thermal response time enabling the sensor to be heated for a very brief period during measurement. This "pulsed heating" mode of microheater-based sensors provides a further reduction in the power consumption.

Here we present the design and fabrication of a new generation of SMO gas sensors combining low power consumption MEMS microheaters and pulsed heating operation, pushing the average power consumption down to microwatts. The fabrication process is fully compatible with the commercialized Poly-MUMPs ${ }^{\circledR}$ process, facilitating the integration with other types of MEMS sensors and actuators for low cost, mass production and mobile applications. We first present a new optimization scheme of the heater dimensions based on a heat transfer analysis of the system. The microfabrication process is then 
presented. The fabricated heaters are tested with both transient and steady-state response, showing a low power consumption $(\sim 2 \mathrm{~mW})$ and fast thermal response time $(\sim 33 \mu \mathrm{s})$. While the steady state power consumption is among the lowest in MEMS heater based gas sensors [3], our transient response time is significantly lower than similar microheaters, which usually have millisecond-level response time[3,27,28]. We leverage this ultrafast thermal response time to heat the microheater for millisecond periods every second, bringing the average power consumption to as low as $2 \mu \mathrm{W}$. Finally, we present sensing results from these microheater-based sensors coated with $\mathrm{WO}_{3}$ nanoparticles while operating in this ultra-low power heat pulse mode.

\section{Microheater Design}

Joule heating is utilized to heat the microheaters due to its simplicity in implementation. Polysilicon is chosen as the resistive heating material for its tunable resistivity, compatibility with micromachining processes, and its high resistance to electromigration[28-30]. The major design goal of the microheaters presented here is to maximize the thermal efficiency, i.e., minimize the power consumption to reach a given temperature. Therefore, understanding the heat loss mechanisms is paramount. Heat loss to the supporting substrate usually dominates the power consumption of microheaters. We, therefore, adopt the typical "suspended beam" design to minimize thermal contact between the heater and substrate (Figure 1).

\section{FIGURE 1}

Suspended beam heaters have been investigated exhaustively in gas sensors[5,11-17,27]. In a typical design analysis, the main heat loss mechanism is usually considered as the heat conduction through the beam to the beam anchors, which are treated as heat sinks due to their direct contact with the substrate. Heat loss through convection and conduction of the surrounding gas and through radiation is often neglected in larger sized heaters[31]. This traditional treatment is, however, not suitable for our heater design, because (i) the beam is ultra-thin $(200 \mathrm{~nm})$, so heat conduction through the beam is relatively small; and (ii) the beam dimensions are small, so heat conduction through air is relatively high due to the high surface area to volume ratio and high temperature gradient near the beam[32]. A detailed analytical analysis is provided below.

\subsection{Analytical Model}

The heat loss through conduction of the beam can be estimated as:

$$
P_{\text {badm }} \approx \frac{\text { sarkwz }}{L}
$$

where $\Delta T$ is the temperature difference between the beam center and the anchor, $L$ is the length of the beam, $k$ is the thermal conductivity of the beam material, $w$ is the width of the beam, and $t$ is the thickness of the beam. This rough estimation assumes a parabolic temperature distribution from the end of the beam at room temperature to the center of the beam where the maximum temperature is reached, so that the temperature gradient along the beam direction near the anchor is simply $4 \Delta T / L$. The heat flow will 
be the gradient times the cross sectional area of the beam times the thermal conductivity of the material. The final factor of 2 arises from the two anchors of the beam.

To estimate the heat loss through air, we first identify the temperature profile of the air around the microheater. Because the heater is long and thin $(t, w<<L)$, the heat loss can be estimated as twodimensional heat conduction in the planes perpendicular to the length direction of the beam. For modeling purposes, the beam is treated as a cylinder with diameter $w$, length $L$, and temperature $\Delta T$ above the environment. The temperature profiles in the planes perpendicular to the length direction of the beam are obtained by solving the two-dimensional Poison equation

$$
T=\frac{\ln \left(D_{\infty} / 2\right)-\ln w}{\ln D_{\infty}-\ln w} \Delta T
$$

where $D_{\infty}$ is the diameter in the radial direction at which the temperature approaches ambient temperature, and $r$ is the radial axis of the cylindrical coordinate centered around the beam axis. The heat conduction through air is therefore

$$
P_{\text {air }}=\oiint k_{\text {air }} \frac{\partial T}{\partial r} d A=\left.k_{\text {air }} \frac{\partial T}{\partial r}\right|_{r=D / 2} \frac{\pi w L}{2}
$$

where $k_{\text {air }}$ is the thermal conductivity of air and the factor of 2 in the denominator reflects the maximum temperature being at the center of the beam. For the same reason $D_{\infty}$ can be approximated as $L$, since beyond $L$ the temperature of the air quickly drops to the ambient temperature. With these approximations and by substituting Equation (2) into (3), the power lost to the surrounding air becomes

$$
P_{\text {air }}=\frac{\pi k_{\text {air } L}}{\ln (L / w)} \Delta T
$$

Combining Equation (1) and (4), the total power consumption is:

$$
P=P_{\text {air }}+P_{\text {beam }}=\Delta T\left(\frac{\pi k_{\text {air }} L}{\ln (L / w)}+\frac{B k w t}{L}\right)
$$

\section{FIGURE 2}

The beam length may be optimized for the lowest power consumption (Figure 2), when the other parameters are fixed due to fabrication considerations (i.e. $t=200 \mathrm{~nm}$, due to film stress and mechanical strength consideration; and $w=2 \mu \mathrm{m}$, due to photolithography and alignment resolution, and sensing layer deposition requirements. For the given set of parameters, the optimum beam length is $\sim 100 \mu \mathrm{m}$, which results in a power consumption of $\sim 2 \mathrm{~mW}$ to reach $300^{\circ} \mathrm{C}$. This optimum length corresponds to the point when equal amounts of heat are lost through the air and through the substrate. Shorter beam lengths result in a disproportionately larger heat loss through the beam compared to the decrease in heat lost to the air. For greater beam lengths, a disproportionately larger amount of heat is lost through the air compared to the decrease in heat lost to the substrate. Therefore, this analytical result provides a method 
for optimizing the thermal efficiency of microheater beams by balancing the heat loss to the air and to the substrate.

\subsection{Finite Element Analysis Simulation}

To further support the analytical calculation, a simulation is performed in ANSYS $^{\circledR}$ (Figure 3) with the optimized parameters. The simulation gives a total power consumption of $2.5 \mathrm{~mW}$, with $1.2 \mathrm{~mW}$ lost through beam conduction, and $1.3 \mathrm{~mW}$ lost through air conduction, in good agreement with the analytical analysis. To verify the prediction of our analytical model that this is the minimal power to support $300{ }^{\circ} \mathrm{C}$ operation, we also simulated the power consumption at various beam lengths from $40 \mu \mathrm{m}$ to $140 \mu \mathrm{m}$. The results can be found in Fig.2. The data from simulation shows that the minimal power consumption is acquired at beam length somewhere between $80 \mu \mathrm{m}$ and $100 \mu \mathrm{m}$, which agrees well with our analytical model.

\section{FIGURE 3}

For gas sensor fabrication, two more components are added to the microheaters: sensing electrodes for contacting the gas sensing layer and a temperature sensor. Sensor electrodes are deposited on top of the microheater beam with a separation of $2 \mu \mathrm{m}$ or $4 \mu \mathrm{m}$ at the midpoint of the beam. This ensures that the changes in the measured resistance is dominated by the sensing material at the hottest point of the microheater. Two methods are used for temperature sensing: resistive temperature detector (RTD) and thermal couple (TC). For the RTD method, Pt is chosen as the temperature sensing element, due to its large thermal coefficient of resistance $\left(3.73 \times 10^{-3}\right.$ near room temperature $)$ and its linear temperature response over a wide temperature range. For the TC method, $\mathrm{Pt}$ is used as one electrode material and gold $(\mathrm{Au})$ is used for the other electrode. Pt-Au TC is a standard combination with tabulated output numbers $[33,34]$ and both metals are resistant to silicon etching during the fabrication process.

Several parameters are varied through the different sensor designs. The beam widths include 2 $\mu \mathrm{m}, 4 \mu \mathrm{m}, 8 \mu \mathrm{m}, 10 \mu \mathrm{m}$, and $16 \mu \mathrm{m}$; The beam lengths include $56 \mu \mathrm{m}, 80 \mu \mathrm{m}$, and $110 \mu \mathrm{m}$; The temperature sensors include average Pt RTD, Pt RTD at heated region contacted by Au electrodes, and Pt$\mathrm{Au}$ TC. The gas sensing electrode gaps are either $2 \mu \mathrm{m}$ or $4 \mu \mathrm{m}$. In total, 27 different design variations of the sensor are fabricated. Figure 4 shows one of them. Note that the previous modeling of the microheater as a $200 \mathrm{~nm}$ thick polysilicon beam is an equivalent model used to approximate the thermal properties of the actual microheater consisting of layers of different materials (100 nm poly-Si, $200 \mathrm{~nm}$ $\mathrm{Si}_{3} \mathrm{~N}_{4}, 60 \mathrm{~nm}$ Pt, etc.)

\section{FIGURE 4}

\section{Device Fabrication}

The fabrication of the microheaters is a 4-mask surface micromachining process followed by a $\mathrm{KOH}$ etch to release the suspended beam structure. Seventy-two (72) microheaters are integrated onto each sensor chip with an area of $3.2 \mathrm{~mm} \times 3.0 \mathrm{~mm}$. The microheater fabrication process is illustrated in Figure 5. First, a $100 \mathrm{~nm}$ thick layer of silicon-rich low-stress nitride (LSN) is deposited by low pressure chemical vapor deposition (LPCVD) process onto a 4" silicon wafer, followed by a $100 \mathrm{~nm}$ thick layer of in-situ doped polysilicon and $2 \mu \mathrm{m}$ boron doped silicon dioxide. The wafers are then heated to $1050{ }^{\circ} \mathrm{C}$ 
for film stress release, dopant diffusion, and dopant activation within the polysilicon layer. The oxide layer is then removed using a buffered hydrogen fluoride (BHF) etch bath (Figure 5a). The sheet resistance of the polysilicon is measured to be $38 \Omega /$ sq. $1-\mu \mathrm{m}$ Fujifilm ${ }^{\circledR}$ OiR 897 photoresist is spun on the substrate and patterned using photolithography (mask 1, Figure $5 \mathrm{~b}$ ). The polysilicon layer and the LSN layer are sequentially etched using a plasma etcher, where the photoresist serves as the etching mask. The photoresist is then stripped off with acetone and the wafers are cleaned in piranha solution ( Figure 5c). Another 100-nm-thick LSN layer is deposited ( Figure 5d) and again patterned using the photolithography-etching-cleaning technique (mask 2, Figure 5e) to encapsulate the polysilicon microheater. Metals are then deposited onto the devices to create the sensor leads and the temperature detection element and make electrical contact to the microheaters. To do this, another photoresist layer is spun on and patterned (mask 3), and 1.2/60nm thick chromium/platinum layer is e-beam deposited onto the substrate. The chromium layer is used as an adhesion layer between the substrate and platinum. The metal layer is patterned following a lift-off process in acetone in an ultrasonic bath (Figure 5f). The wafers are then annealed in nitrogen environment at $350{ }^{\circ} \mathrm{C}$ for 1 hour to release Pt film stress. A similar photolithography-evaporation-lift off process is carried out to deposit another patterned layer of $1.2 / 100 \mathrm{~nm}$ thick chromium/gold (mask 4, Figure $5 \mathrm{~g}$ ). Finally, the wafers are diced into individual chips and the suspended microheater beam is released by etching the underlying silicon substrate in a $\mathrm{KOH}$ bath at $80{ }^{\circ} \mathrm{C}$ (Figure $5 \mathrm{~h}$ ). To facilitate the $\mathrm{KOH}$ release process, the beams are all angled at 45 degrees so that the etching of silicon substrate can proceed freely underneath the beam without hitting the $<111>$ plane where the etch rate is very low[35].

\section{FIGURE 5}

The nanoparticle sensing layer is deposited using precision solution deposition or by shadow mask evaporation. For small batch testing, we first use sharp porous cellulose-based tips to soak up nanoparticle suspension, and then use micromanipulator to move the tip into contact with the microheater for the deposition of the nanoparticles. The porous cellulose-based tip is soft enough to safely contact the suspended heaters without breaking them and can store sufficient amount of solvent to avoid drying during deposition. For mass production, shadow mask deposition can be carried out sequentially to allow the integration of a multi-functional sensor array in one sensor chip[2]. Using this method, the sensing layer is shadow mask deposited either by evaporating metal oxide (e.g. zinc oxide, tin oxide, or tungsten oxide) directly or by first evaporating a thin layer of metal $(\sim 20 \mathrm{~nm})$, which is subsequently oxidized in air at $180{ }^{\circ} \mathrm{C}$.

\section{Microheater Characterization}

\subsection{Steady State Characterization}

Figure 6 shows SEM images of the fabricated microheater arrays. The microheater arrays (Fig. 6, upper left) consist of eight rows of microheaters. Each row contains nine microheaters suspended over a trench of approximately $20 \mu \mathrm{m}$ in depth. The individual microheater devices (Fig. 6, right) each contain 6 electrical contacts: two for microheater source and drain, two for the sensing electrode pair, and two contacts for the temperature sensor, either an RTD or a TC (Fig. 6, bottom left). The sensing electrodes 
have a gap of $2 \mu \mathrm{m}$ at the center of the beam to probe the electrical properties of the to-be-deposited sensing layer at the hottest region of the microheater. The microheater is angled at $45^{\circ}$ to facilitate underetching by the anisotropic $\mathrm{KOH}$ etch.

\section{FIGURE 6}

For electrical characterization, the microheaters are mounted into a chip carrier and electrical contact are made with the microheater, sensor electrode and temperature sensor via wire bonding. A device absolute-maximum-rating test was performed on a microheater with the following parameters: beam width: $10 \mu \mathrm{m}$; length: $110 \mu \mathrm{m}$; trench width: $74 \mu \mathrm{m}$. The microheater voltage is increased until the device fails. To roughly gauge the temperature of the microheater prior to failure, the optical emission of the device is observed. At a bias voltage of $8.7 \mathrm{~V}$, corresponding to a power of $34 \mathrm{~mW}$, the microheater has a bright orange color (Figure 7), which is estimated to be roughly $950{ }^{\circ} \mathrm{C}$. (see Figure 9 for the optical method used for temperature measurement). The heater fails at a bias of $9 \mathrm{~V}$. This test demonstrates that the thermal stability of the microheater heater is sufficient to cover the temperature range for SMO sensor operation $\left(250{ }^{\circ} \mathrm{C}-450{ }^{\circ} \mathrm{C}\right)$.

\section{FIGURE 7}

To more accurately measure the temperature, microheaters are equipped with resistive temperature detectors (RTD) or thermal couples (TC). Figure 8 shows data collected from the resistive temperature detector (RTD) and thermal couple (TC) of $10 \mu \mathrm{m}$ wide and $80 \mu \mathrm{m}$ long devices. Figure $8 \mathrm{a}$ shows the resistance of a platinum RTD versus microheater bias voltage. Figure $8 \mathrm{~b}$ shows the output voltage from a gold-platinum TC versus microheater bias voltage. The RTD and TC measurements should have a linear dependence on temperature. When radiation power can be neglected (as in this case), temperature is linearly proportional to input power. Therefore, these data should have a quadratic dependence on bias voltage (red curve). At voltages below $4 \mathrm{~V}$, the data fit the quadratic curve quite well, with coefficient of determination $\left(\mathrm{R}^{2}\right)$ to be 0.9961 for $\mathrm{RTD}$ data and 0.9972 for TC data. At higher voltages, Joule heating induces non-negligible phonon scattering, which increases the microheater resistance, causing the temperature sensor reading to deviate from the quadratic fit. According to the $\mathrm{RTD}$ reading (the resistance of $\mathrm{Pt}$ at $300^{\circ} \mathrm{C}$ is $\sim 2.0$ times the one at room temperature), the heater temperature reaches $\sim 300{ }^{\circ} \mathrm{C}$ with $5.0 \mathrm{~V}$ supply voltage, $1.4 \mathrm{~mA}$ current, and $6.8 \mathrm{~mW}$ power consumption. Note that the power consumption is higher than in the previous calculation and simulation, since the microheater used in the test is much wider $(10 \mu \mathrm{m})$.

\section{FIGURE 8}

Some microheaters are designed without integrated temperature sensors, so that they are narrower $(2 \mu \mathrm{m})$ to achieve maximal thermal efficiency. Here we describe an optical method used measure the temperature of the microheater in the absence of an embedded temperature sensing element. Briefly, a spectrometer (Renishaw ${ }^{\circledR}$ RM1000) is used to measure the local thermal radiation spectrum of the microheater. First, one of the microheaters is located and centered under the objective of the spectrometer with illumination on. Next, the illumination is turned off and we slowly ramp up the voltage applied on the microheater until we see the microheater glowing. The radiation spectrum is collected by the spectrometer with a "high-confocal" option to locally measure the temperature ( $\sim 5 \mu \mathrm{m}$ area according to manufacturer's manual). We model the thermal radiation from the microheater as gray body radiation (i.e. 
constant emissivity in the photon energy range of $1.5 \mathrm{eV} \sim 1.9 \mathrm{eV}$ ). The temperature of the microheater is calculated by fitting to a Planck distribution. Figure 9 shows emission spectra collected at two different microheater powers and the corresponding fit to a Planck distribution. Figure 9a shows data collected at the onset of glowing. Fitting to a Planck distribution gives a calculated temperature of $682{ }^{\circ} \mathrm{C}$. When driving the microheater to higher temperatures, the emitted spectrum also fits well to a Planck distribution. Figure $9 \mathrm{~b}$ shows data collected when the microheater device is glowing bright reddish orange, giving a calculated temperature of $892{ }^{\circ} \mathrm{C}$.

\section{FIGURE 9}

Assuming constant heat conduction and using Equation (5), we can deduce the power required to reach $300{ }^{\circ} \mathrm{C}$, since there is a linear proportionality between relative temperature and power. Therefore, a heater with $2 \mu \mathrm{m}$ width and $80 \mu \mathrm{m}$ length, which begins to glow (i.e. reach $700{ }^{\circ} \mathrm{C}$ ) at $5.2 \mathrm{~mW}$, can be heated to $300{ }^{\circ} \mathrm{C}$ with a power of $2.1 \mathrm{~mW}$ for an ambient temperature of $20^{\circ} \mathrm{C}$.

\subsection{Dynamic Response Characterization}

Power consumption is further reduced by operating the microheater in heat pulsing mode[26], in which the heater is powered on for only a fraction of the time. The average power consumption can therefore be proportionally reduced. Our previous studies[26] reveal that an on-off time ratio of 1:5 does not affect the sensor performance. Using the same on-off time ratio, the microheaters will only consume approximately $350 \mu \mathrm{W}$ average power when being pulsed to $300{ }^{\circ} \mathrm{C}$. However, if the thermal response time of the microheaters is reduced, the duration of the heat pulse can be correspondingly reduced resulting in lower duty cycling and, therefore, lower power consumption.

To assess the thermal response time of the microheater presented in this work, we characterized the transient electrical response of the microheater to changes in bias voltage. A short thermal response time of the microheaters is critical for low duty cycle heat pulse operation. Measurement of the thermal response time of the microheaters is necessary to determine a minimum width of a heat pulse. Here we use a resistance measurement method to determine the thermal time constant of the microheaters, which exploits the temperature dependence of the electrical resistivity of polysilicon. The circuit diagram is illustrated in Figure 10(a). A signal generator creates a square wave that toggles between $V_{\max }$ and $V_{\min }$. The square wave voltage signal is buffered by a power amplifier with low output resistance to drive the microheaters. A resistor $\mathrm{R}_{\mathrm{i}}<<\mathrm{R}_{\text {heater }}$ is connected in series with the microheater to monitor the current flowing through the microheater. The voltage drop on $\mathrm{R}_{\mathrm{i}}$ is amplified using a buffer amplifier connected to an oscilloscope, where a voltage proportional to the current flow through the microheater is displayed and analyzed.

\section{FIGURE 10}

According to Equation (5), power loss to the environment from the microheater is linearly proportional to the heater temperature above ambient and can be therefore described as

$$
P_{\operatorname{logs}}(T)=k_{\theta} T
$$


where $k_{e}$ is the heat conductance from the microheater to the environment, and $T$ is the temperature of the microheater (with respect to the ambient temperature). The steady state microheater temperature is defined to be $T_{\max }$ when the driving voltage is at $V_{\max }$, and $T_{\min }$ at $V_{\min }$. If at $\mathrm{t}=0$ the driving voltage changes from $V_{\max }$ to $V_{\min }$, the change in temperature of the microheater is described by

$$
C \frac{d T}{d t}=P_{\text {in }}-P_{\operatorname{loss}}(T)
$$

where $C$ is the total heat capacity of the microheater. Here $P_{\text {in }}$ is the input power corresponding to a steady state heater temperature of $T_{\min }$, so $P_{\text {in }}=P_{\text {loss }}\left(T_{\min }\right)=k_{e} T_{\min }$. Plugging this into Equation (6), we have

$$
C \frac{d T}{d t}=k_{g} T_{\min }-k_{g} T
$$

Solving this equation with boundary condition $T(t=0)=T_{\max }$ and $T(t=\infty)=T_{\min }$, the temperature of the microheater is observed to follow exponential behavior

$$
T=\left(T_{\max }-T_{\min }\right) e^{-\frac{t}{\tau}}+T_{\min }
$$

where $\tau=C / k_{e}$ is the thermal time constant. Assuming a linear temperature coefficient of the electrical conductivity of polysilicon in the vicinity of $T_{\min }$ and $T_{\max }$, we see that the current flow through the microheater would follow the same exponential behavior and the thermal time constant of the microheater can therefore be extracted from the transient response of the microheater resistance. We note that the electrical RC time constant will also affect the transient response to this voltage change. However, the RC time constant is on the order of nanoseconds, since $R_{\text {heater }}$ is in $\mathrm{k} \Omega$ range and parasitic capacitance of the heater is in $\mathrm{pF}$ range, and can be neglected. Figure $10 \mathrm{~b}$ shows the output voltage versus time when the voltage changes from $\mathrm{V}_{\min }$ to $\mathrm{V}_{\max }$ (upper) and vice versa (lower) for a microheater with $10 \mu \mathrm{m}$ width and $80 \mu \mathrm{m}$ length. The insets show the exponential fittings to the data. The data fit well to the exponential curves and the extracted time constant for this heater is $76 \pm 2 \mu \mathrm{s}$. The smaller heaters have even shorter time constants due to smaller heat capacity of the heaters. For example, the $2 \mu \mathrm{m}$ wide, $56 \mu \mathrm{m}$ long microheaters is measured to have a time constant of $33 \pm 4 \mu \mathrm{s}$. Such a short thermal time constant allows the microheater to operate at very short pulses, potentially resulting in ultra-low average power consumption.

\section{Gas Sensor Characterization}

The lower power microheater described here is functionalized with $\mathrm{WO}_{3}$ nanoparticles via precision solution deposition (described above) to create a hydrogen sulfide $\left(\mathrm{H}_{2} \mathrm{~S}\right)$ sensor. This material system has been previously shown to be an effective $\mathrm{H}_{2} \mathrm{~S}$ sensor using a commercially available microheater with a peak power consumption of $40 \mathrm{~mW}$ to reach $300^{\circ} \mathrm{C}[26]$. This previous study showed that the electrical conductance of the networks of $\mathrm{WO}_{3}$ nanoparticles increased when exposed to $\mathrm{H}_{2} \mathrm{~S}$ when heated to $300^{\circ} \mathrm{C}$. Furthermore, these sensors can be heated with short voltage pulses to decrease the average power 
consumption. Here we describe a similar result achieved with much lower power consumption with the microheater devices described in this work.

Figure 11 shows the current through a $\mathrm{WO}_{3}$ nanoparticle network deposited on the microheater bridge as the device is heated to $300^{\circ} \mathrm{C}$ for one second every six seconds. As the sensor is heated, the current increases, due to the semiconducting nature of $\mathrm{WO}_{3}$ and this "heater on" current is increases upon exposure to $\mathrm{H}_{2} \mathrm{~S}$ concentration. The peak power consumption for this device is $1.5 \mathrm{~mW}$ resulting in an average power consumption of only $250 \mu \mathrm{W}$. This is roughly 3 orders of magnitude lower than commercial SMO sensors. Microheaters operating in "pulsed heating" mode at $300^{\circ} \mathrm{C}$ have been shown to operate for over three months with the resistance varying by less that $5 \%$ in that time.

\section{FIGURE 11}

Given the fast thermal response of the microheaters described in this work, these heat pulses can be shortened to the millisecond regime. Figure 12a shows the sensor conductance (during the heated phase only) for 1-ms heat pulses versus time. This microheater has a peak power consumption of about $1.5 \mathrm{~mW}$ to attain a temperature of $300^{\circ} \mathrm{C}$, which is the optimal operating temperature for this sensor. The $1-\mathrm{ms}$ heat pulses are applied once a second, giving an average power consumption of only $1.5 \mu \mathrm{W}$. This level of power consumptions is reaching the range of electrochemical sensors with a much simpler method of fabrication and assembly, much smaller form factor, and composed of robust, high temperaturecompatible materials.

\section{FIGURE 12}

While the response of the sensor for the ultra-short heat pulses is not as fast as with longer heat pulse times ( $\tau \sim$ minutes, not seconds), this mode of measurement could be used to "monitor" the environmental conditions. If the sensor conductance begins to respond after exposure to $\mathrm{H}_{2} \mathrm{~S}$ like shown in Figure 12a, the heat pulse duration can be increased. The response time decreases when the heat pulse duration is increased $100 \mathrm{~ms}$, as shown in Figure 12b. Here the response time of the sensor has decreased from the order of minutes to about 10 seconds. A likely reason for this decrease in response time is that the chemical reactions at the root of the sensing mechanism have reaction rates much slower than the thermal response of the microheater.

\section{CONCLUSION}

We have demonstrated an ultra-low power, fast responding microheater based gas sensor platform. The ultra-low power operation is a result of combining the two advantages gained through miniaturization: (1) the drastic reduction in microheater surface area reduces the peak power to approximately $1 \mathrm{~mW}$, and (2) the short response time of tens of $\mu$ s allows the sensor to be heated with short pulses, resulting in an average power consumption of as low as $1.5 \mu \mathrm{W}$. Being compatible with commercialized Poly-MUMPs ${ }^{\circledR}$ process, the gas sensing microheater platform presented here can be integrated with other MEMS sensors and actuators, allowing for low-cost mass production. As a proof of concept, this platform is used to create a hydrogen sulfide gas sensor, but it can be used for a wide array of sensing applications, which require thermal activation, such as pellistors. The ultra-low power 
consumption of the microheater platform presented here enables new applications for microheater sensor technology, such as for smart phone-embedded gas sensors and long-term battery powered air monitors.

\section{Acknowledgement}

This work was supported in part by the Director, Office of Energy Research, Office of Basic Energy Sciences, Materials Sciences and Engineering Division, of the U.S. Department of Energy under Contract No. DE-AC02-05CH11231, which provided for sensor design and simulation; and by the National Science Foundation under Grant No. EEC-083819, which provided for the microheater fabrication, sensor testing, and support for W.M. and A.Z.

\section{References}

[1] F.-G. Banica, Chemical Sensors and Biosensors: Fundamentals and Applications, John Wiley \& Sons, 2012. doi:10.1002/9781118354162.

[2] I. Simon, N. Bârsan, M. Bauer, U. Weimar, Micromachined metal oxide gas sensors: opportunities to improve sensor performance, Sensors Actuators B Chem. 73 (2001) 1-26. doi:10.1016/S09254005(00)00639-0.

[3] S.Z. Ali, F. Udrea, W.I. Milne, J.W. Gardner, Tungsten-based SOI microhotplates for smart gas sensors, Microelectromechanical Syst. J. 17 (2008) 1408-1417. doi:10.1109/JMEMS.2008.2007228.

[4] U. Dibbern, A substrate for thin-film gas sensors in microelectronic technology, Sensors Actuators B Chem. 2 (1990) 63-70. doi:10.1016/0925-4005(90)80010-W.

[5] J.S. Suehle, R.E. Cavicchi, M. Gaitan, S. Semancik, Tin oxide gas sensor fabricated using CMOS micro-hotplates and in-situ processing, IEEE Electron Device Lett. 14 (1993) 118-120. doi:10.1109/55.215130.

[6] M. Zanini, J.H. Visser, L. Rimai, R.E. Soltis, A. Kovalchuk, D.W. Hoffman, et al., Fabrication and properties of a Si-based high-sensitivity microcalorimetric gas sensor, Sensors Actuators A Phys. 48 (1995) 187-192. doi:10.1016/0924-4247(95)01000-9. 
[7] J.W. Gardner, A. Pike, N.F. de Rooij, M. Koudelka-Hep, P.A. Clerc, A. Hierlemann, et al., Integrated array sensor for detecting organic solvents, Sensors Actuators B Chem. 26 (1995) 135139. doi:10.1016/0925-4005(94)01573-Z.

[8] S. Astié, A.M. Gué, E. Scheid, L. Lescouzères, A. Cassagnes, Optimization of an integrated SnO2 gas sensor using a FEM simulator, Sensors Actuators A Phys. 69 (1998) 205-211. doi:10.1016/S0924-4247(98)00096-X.

[9] M.. Horrillo, I. Sayago, L. Arés, J. Rodrigo, J. Gutiérrez, A. Götz, et al., Detection of low NO2 concentrations with low power micromachined tin oxide gas sensors, Sensors Actuators B Chem. 58 (1999) 325-329. doi:10.1016/S0925-4005(99)00092-1.

[10] F. Udrea, J.W. Gardner, D. Setiadi, J.A. Covington, T. Dogaru, C.C. Lu, et al., Design and simulations of SOI CMOS micro-hotplate gas sensors, Sensors Actuators B Chem. 78 (2001) 180190. doi:10.1016/S0925-4005(01)00810-3.

[11] J.C. Belmonte, J. Puigcorbé, J. Arbiol, A. Vilà, J.R. Morante, N. Sabaté, et al., High-temperature low-power performing micromachined suspended micro-hotplate for gas sensing applications, Sensors Actuators B Chem. 114 (2006) 826-835. doi:10.1016/j.snb.2005.07.057.

[12] P.C.. Chan, G. Yan, L. Sheng, R.K. Sharma, Z. Tang, J.K.. Sin, et al., An integrated gas sensor technology using surface micro-machining, Sensors Actuators B Chem. 82 (2002) 277-283. doi:10.1016/S0925-4005(01)01064-4.

[13] E. Barborini, S. Vinati, M. Leccardi, P. Repetto, G. Bertolini, O. Rorato, et al., Batch fabrication of metal oxide sensors on micro-hotplates, J. Micromechanics Microengineering. 18 (2008) 055015. doi:10.1088/0960-1317/18/5/055015.

[14] B. Guo, A. Bermak, P.C.H. Chan, G.-Z. Yan, An Integrated Surface Micromachined Convex Microhotplate Structure for Tin Oxide Gas Sensor Array, IEEE Sens. J. 7 (2007) 1720-1726. doi:10.1109/JSEN.2007.908919.

[15] I. Elmi, S. Zampolli, E. Cozzani, M. Passini, G.C. Cardinali, M. Severi, Development of Ultra Low Power Consumption Hotplates for Gas Sensing Applications, in: 2006 5th IEEE Conf. Sensors, IEEE, 2006: pp. 243-246. doi:10.1109/ICSENS.2007.355767. 
[16] P. Fürjes, C. Dücső, M. Ádám, J. Zettner, I. Bársony, Thermal characterisation of micro-hotplates used in sensor structures, Superlattices Microstruct. 35 (2004) 455-464.

doi:10.1016/j.spmi.2003.09.007.

[17] C. Tsamis, A.G. Nassiopoulou, A. Tserepi, Thermal properties of suspended porous silicon microhotplates for sensor applications, Sensors Actuators B Chem. 95 (2003) 78-82. doi:10.1016/S0925-4005(03)00409-X.

[18] M. Noor, G. Sugandi, Effects of material and membrane structure on maximum temperature of microheater for gas sensor applications, ... Electron. (ICSE), 2014 .... (2014). http://ieeexplore.ieee.org/xpls/abs_all.jsp?arnumber=6920845 (accessed November 03, 2014).

[19] S. Moon, H. Lee, N. Choi, H. Kang, Low Power Consumption Micro C $<\operatorname{sub}>2</$ sub $>\mathrm{H}<\operatorname{sub}>$ $5</$ sub $>$ OH Gas Sensor based on Micro-heater and Ink jetting Technique, Sensors Actuators B .... (2014). http://www.sciencedirect.com/science/article/pii/S0925400514012441 (accessed November 03, 2014).

[20] S. Das, J. Akhtar, Coefficient of Resistance (TCR) of the E-beam and Sputter deposited nichrome thin film for precise temperature control of microheater for MEMS gas sensor, Phys. Semicond. Devices. (2014). http://link.springer.com/chapter/10.1007/978-3-319-03002-9_124 (accessed November 03, 2014).

[21] J. Yadav, V. Mishra, M. Prasad, Design and partial fabrication of low power Pt-based microheater for gas sensing application, INROADS-An Int. .... (2014). http://www.indianjournals.com/ijor.aspx?target=ijor:inroads \&volume $=3 \&$ issue $=1$ s \&article $=051$ (accessed November 03, 2014).

[22] A. Harley-Trochimczyk, J. Chang, Q. Zhou, Catalytic hydrogen sensing using microheated platinum nanoparticle-loaded graphene aerogel, Sensors Actuators B .... (2014). http://www.sciencedirect.com/science/article/pii/S0925400514011265 (accessed November 03, 2014).

[23] F. Hossein-Babaei, A. Amini, Recognition of complex odors with a single generic tin oxide gas sensor, Sensors Actuators B Chem. (2014). http://www.sciencedirect.com/science/article/pii/S0925400513015347 (accessed November 03, 2014). 
[24] H. Kumar, K. Singh, N. Sood, Design and simulation of a Micro Hotplate for MEMS based integrated gas sensing system, Sensors Appl. .... (2014).

http://ieeexplore.ieee.org/xpls/abs_all.jsp?arnumber=6798942 (accessed November 03, 2014).

[25] P. Tyagi, A. Sharma, Reliability and Reproducibility Study on Hand-Held Liquefied Petroleum Gas Sensors Based on Sputtered SnO2 Thin Film and Micro-Heater Using Pt Catalyst, Adv. Sci. .... (2014).

http://www.ingentaconnect.com/content/asp/as1/2014/00000020/F0020005/art00011 (accessed November 03, 2014).

[26] W. Mickelson, A. Sussman, A. Zettl, Low-power, fast, selective nanoparticle-based hydrogen sulfide gas sensor, Appl. Phys. Lett. 100 (2012) 173110. doi:10.1063/1.3703761.

[27] M.Y. Afridi, J.S. Suehle, M.E. Zaghloul, D.W. Berning, A.R. Hefner, R.E. Cavicchi, et al., A monolithic CMOS microhotplate-based gas sensor system, IEEE Sens. J. 2 (2002) 644-655. doi:10.1109/JSEN.2002.807780.

[28] D.-D. Lee, W.-Y. Chung, M.-S. Choi, J.-M. Baek, Low-power micro gas sensor, Sensors Actuators B Chem. 33 (1996) 147-150. doi:10.1016/0925-4005(96)01822-9.

[29] J.R. Black, Electromigration\&\#8212;A brief survey and some recent results, IEEE Trans. Electron Devices. 16 (1969) 338-347. doi:10.1109/T-ED.1969.16754.

[30] I.A. Blech, Electromigration in thin aluminum films on titanium nitride, J. Appl. Phys. 47 (1976) 1203-1208. doi:10.1063/1.322842.

[31] S.K.. Fung, Z. Tang, P.C.. Chan, J.K.. Sin, P.W. Cheung, Thermal analysis and design of a microhotplate for integrated gas-sensor applications, Sensors Actuators A Phys. 54 (1996) 482-487. doi:10.1016/S0924-4247(97)80008-8.

[32] A. Götz, I. Gràcia, C. Cané, E. Lora-Tamayo, M.. Horrillo, J. Getino, et al., A micromachined solid state integrated gas sensor for the detection of aromatic hydrocarbons, Sensors Actuators B Chem. 44 (1997) 483-487. doi:10.1016/S0925-4005(97)00171-8.

[33] Y.-G. Kim, K.S. Gam, K.H. Kang, Thermoelectric properties of the Au/Pt thermocouple, Rev. Sci. Instrum. 69 (1998) 3577-3582. doi:10.1063/1.1149141.

[34] D.C. Ripple, G.W. Burns, Standard Reference Material 1749: Au/Pt Thermocouple Thermometer, NIST Spec. Publ. 260 (1998) 134. 
[35] R. Reay, Thermally and electrically isolated single crystal silicon structures in CMOS technology, Electron Device Lett. .... 15 (1994) 399-401.

http://ieeexplore.ieee.org/xpls/abs_all.jsp?arnumber=320981 (accessed November 03, 2014). 


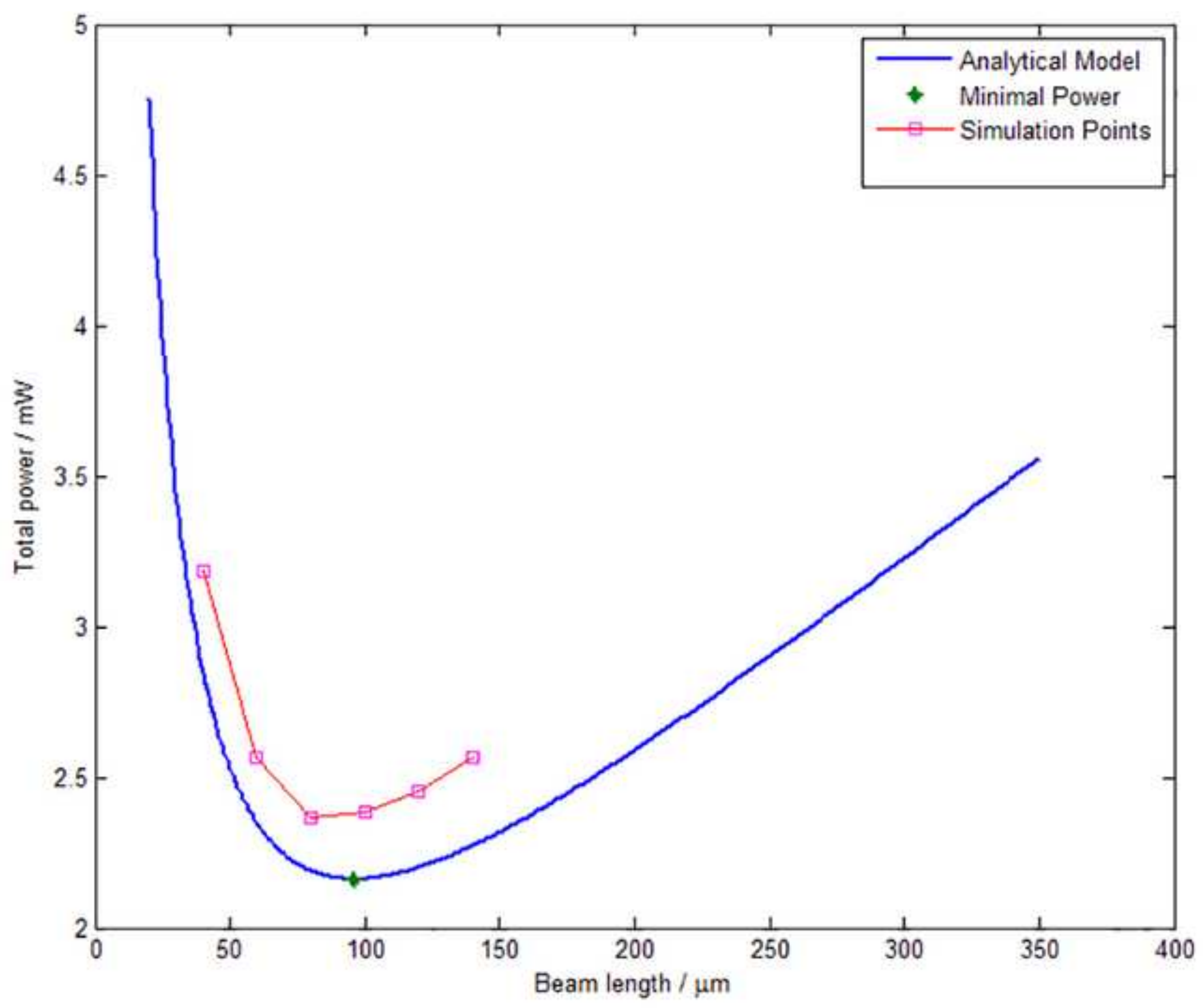

rage $1 /$ or 28 
(a)

(b)

$21 \quad 128 \quad 240 \quad 344^{\circ} \mathrm{C}$

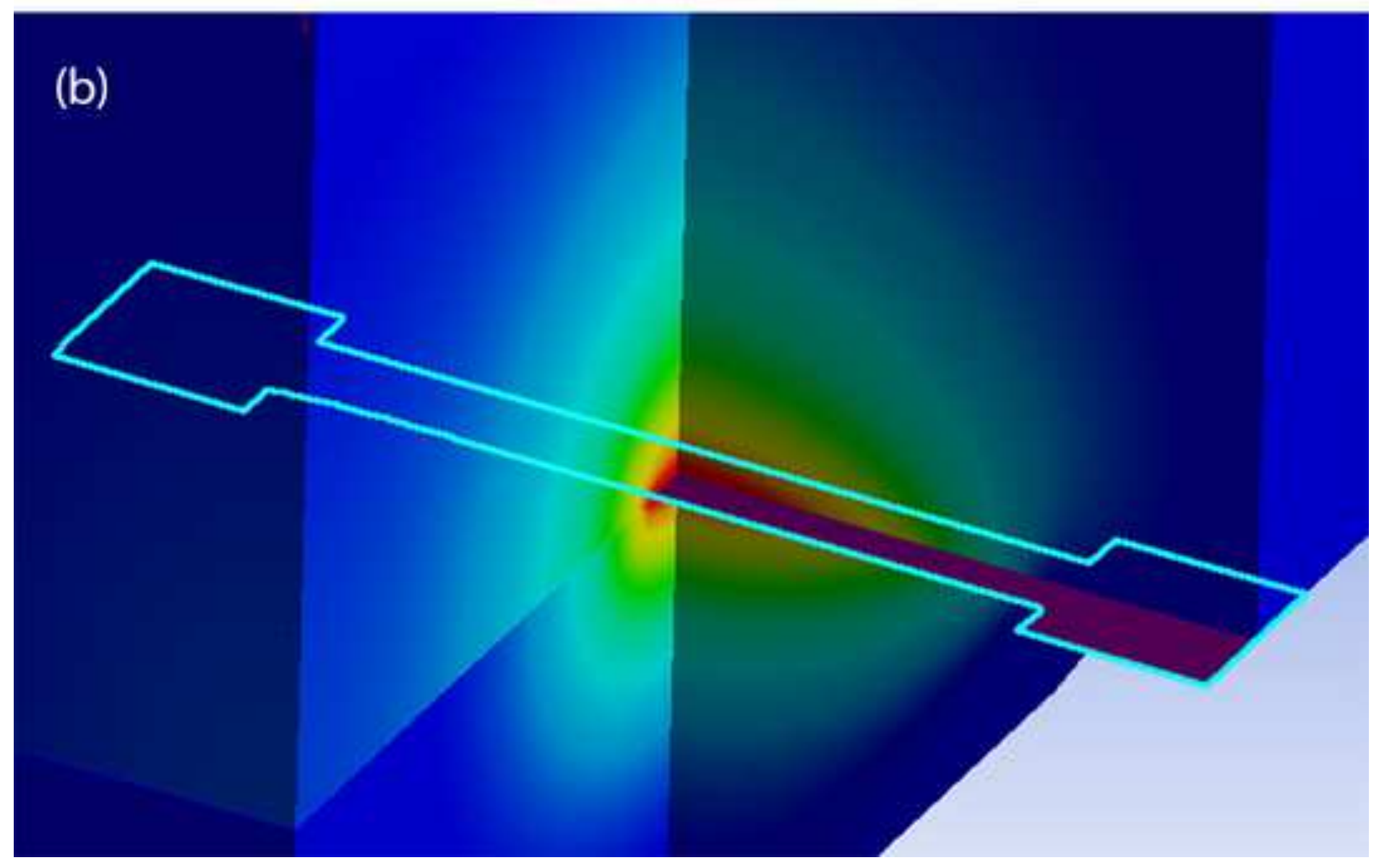

Page 18 of 28

Figure 3

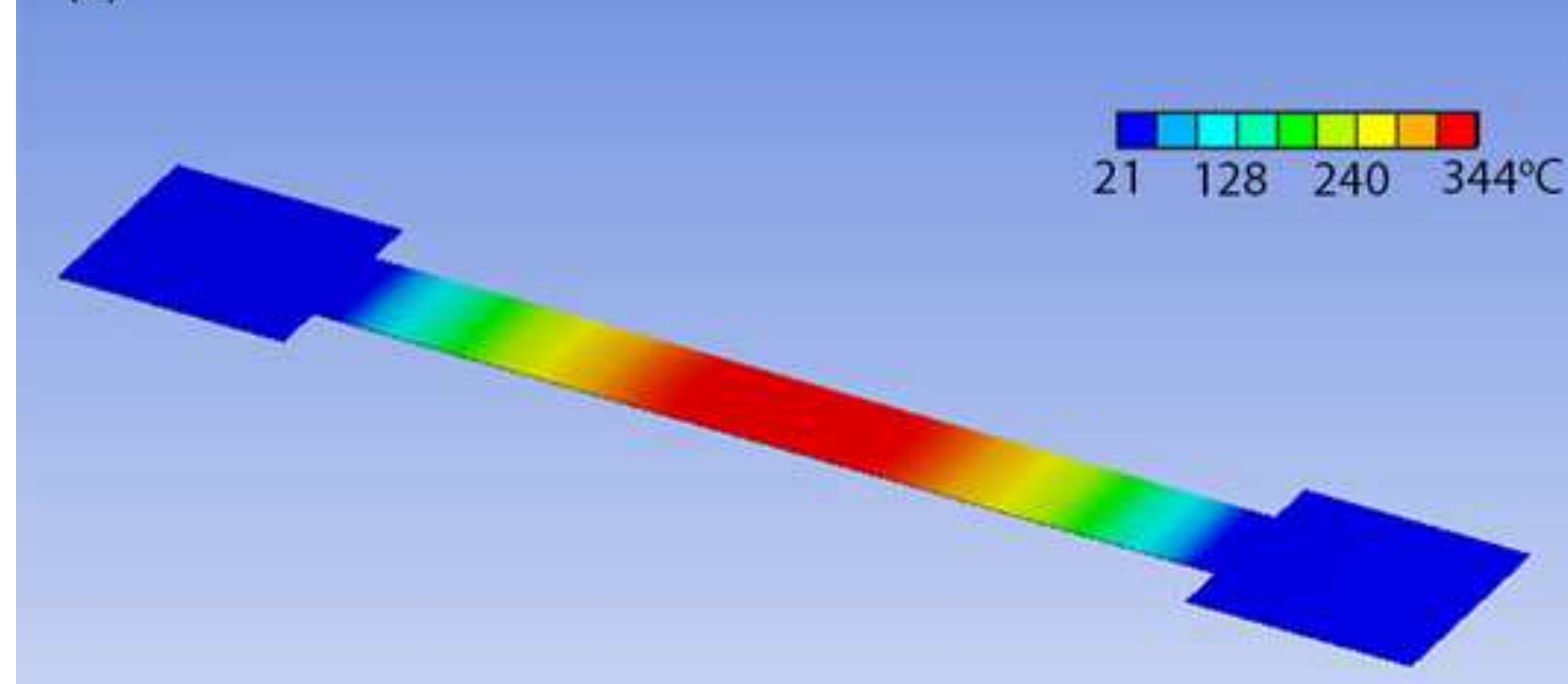


(a)

Thermal couple junction

Sensing gap

(for contacting gas

sensing layer)

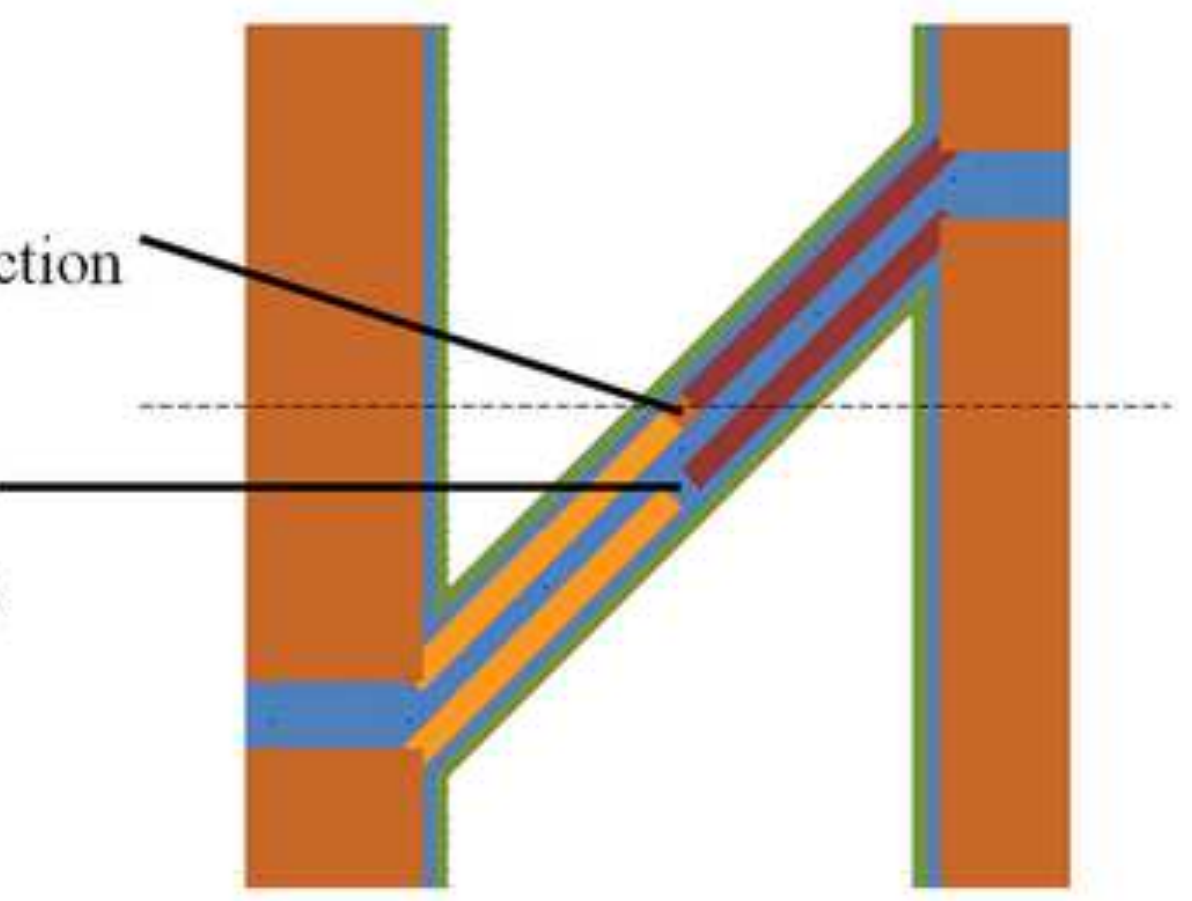

(b)

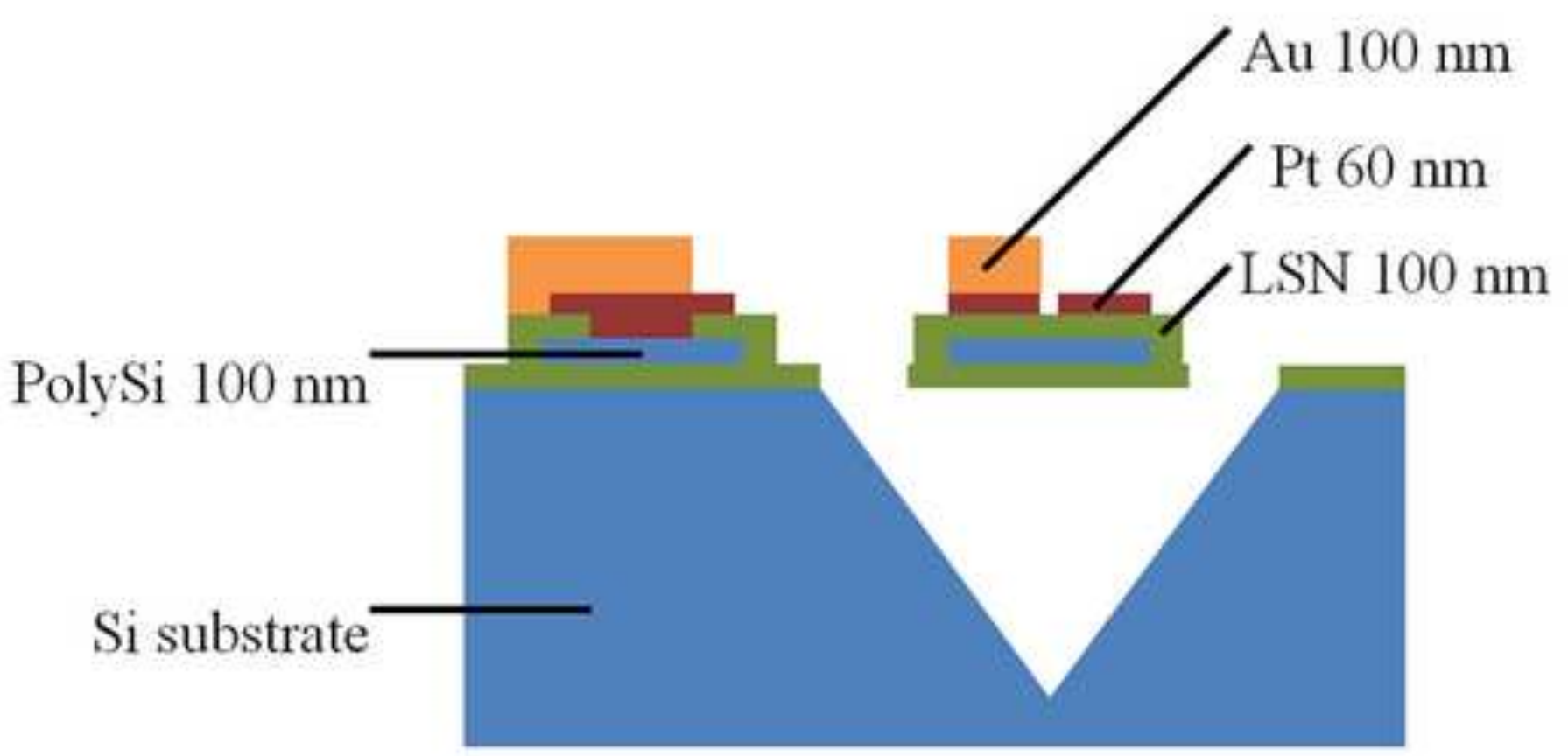

rage $1 y$ or 28 
(a)

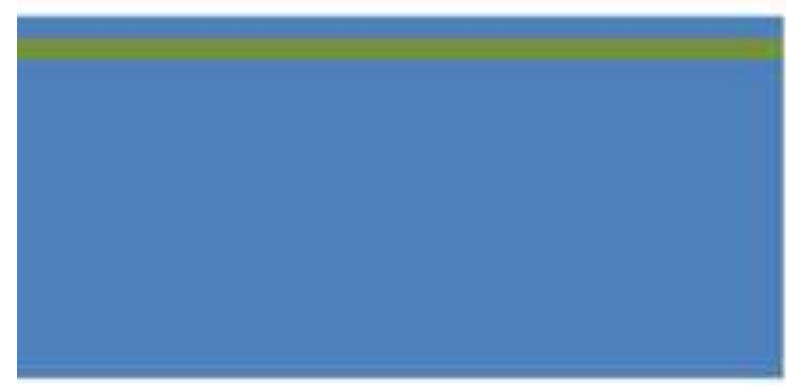

(d)

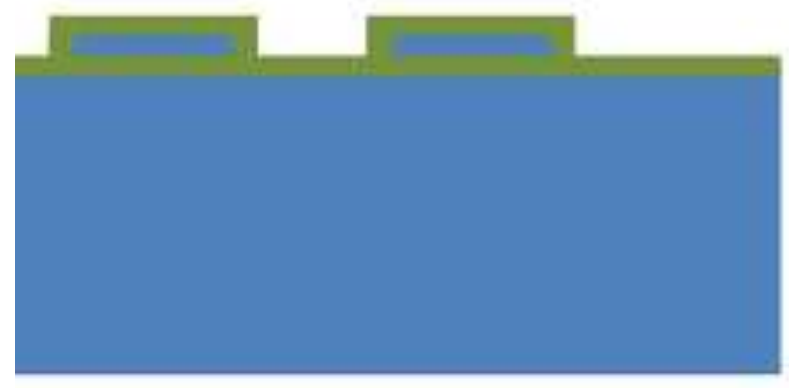

(e)

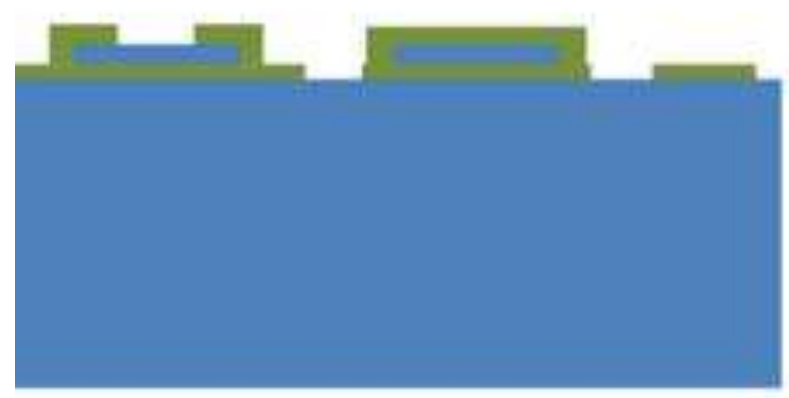

(h)

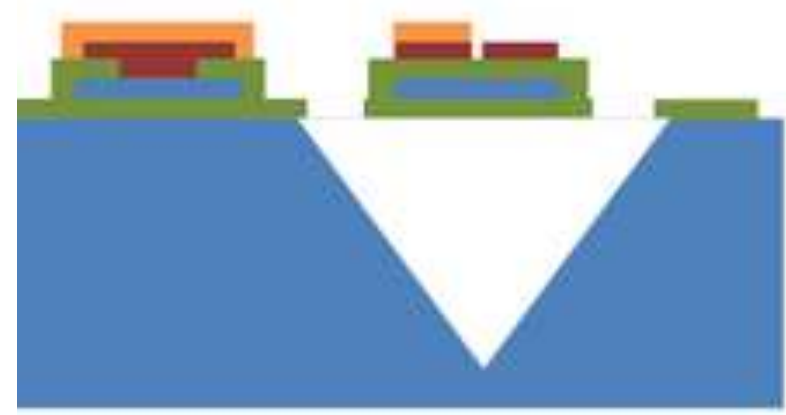

(b)

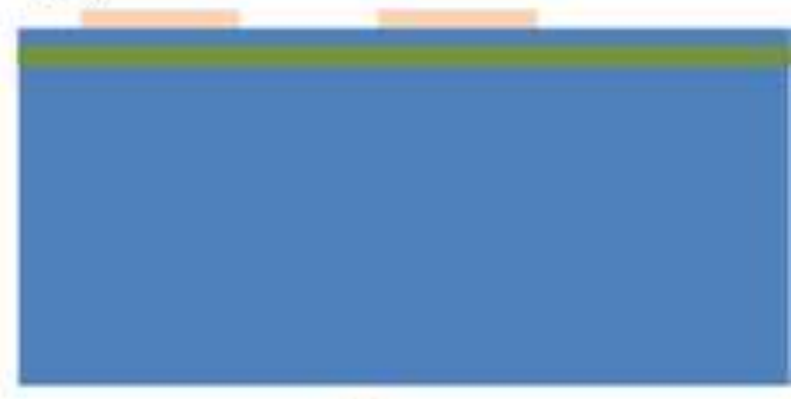

(c)

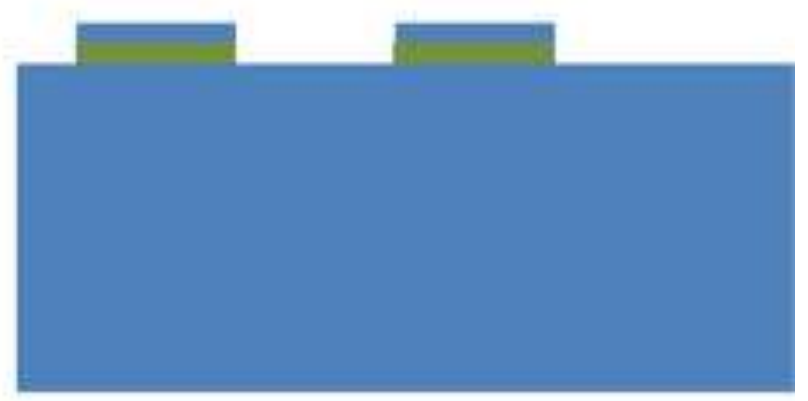

(f)
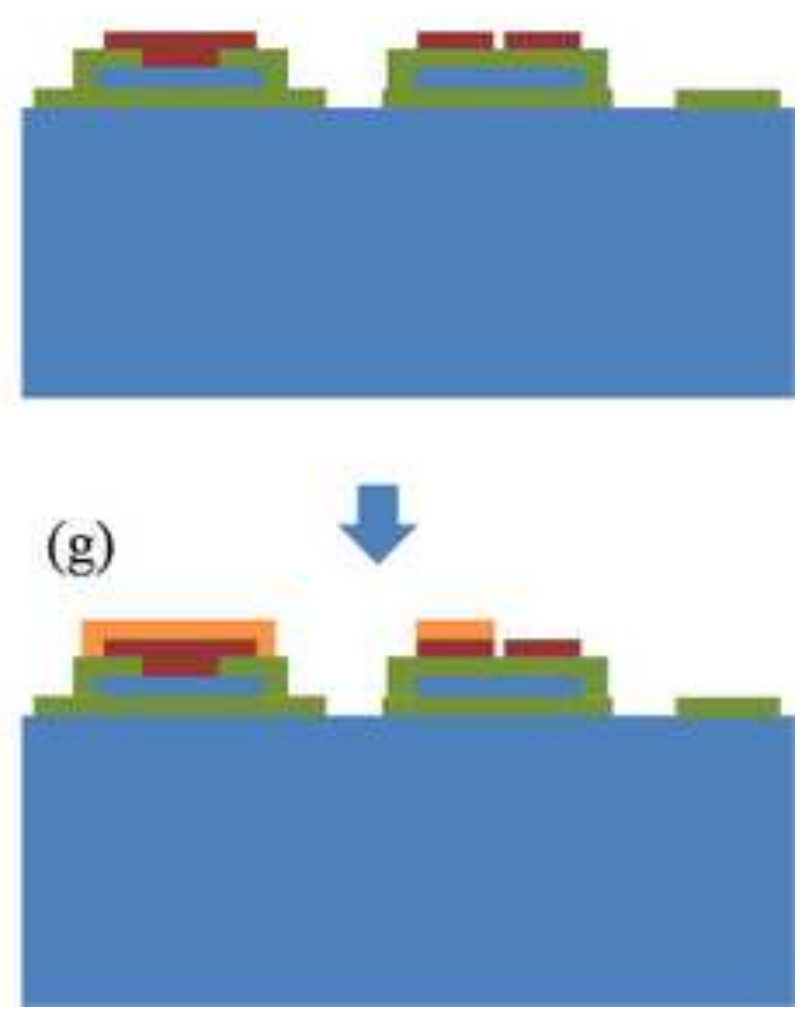

Page 20 of 28 

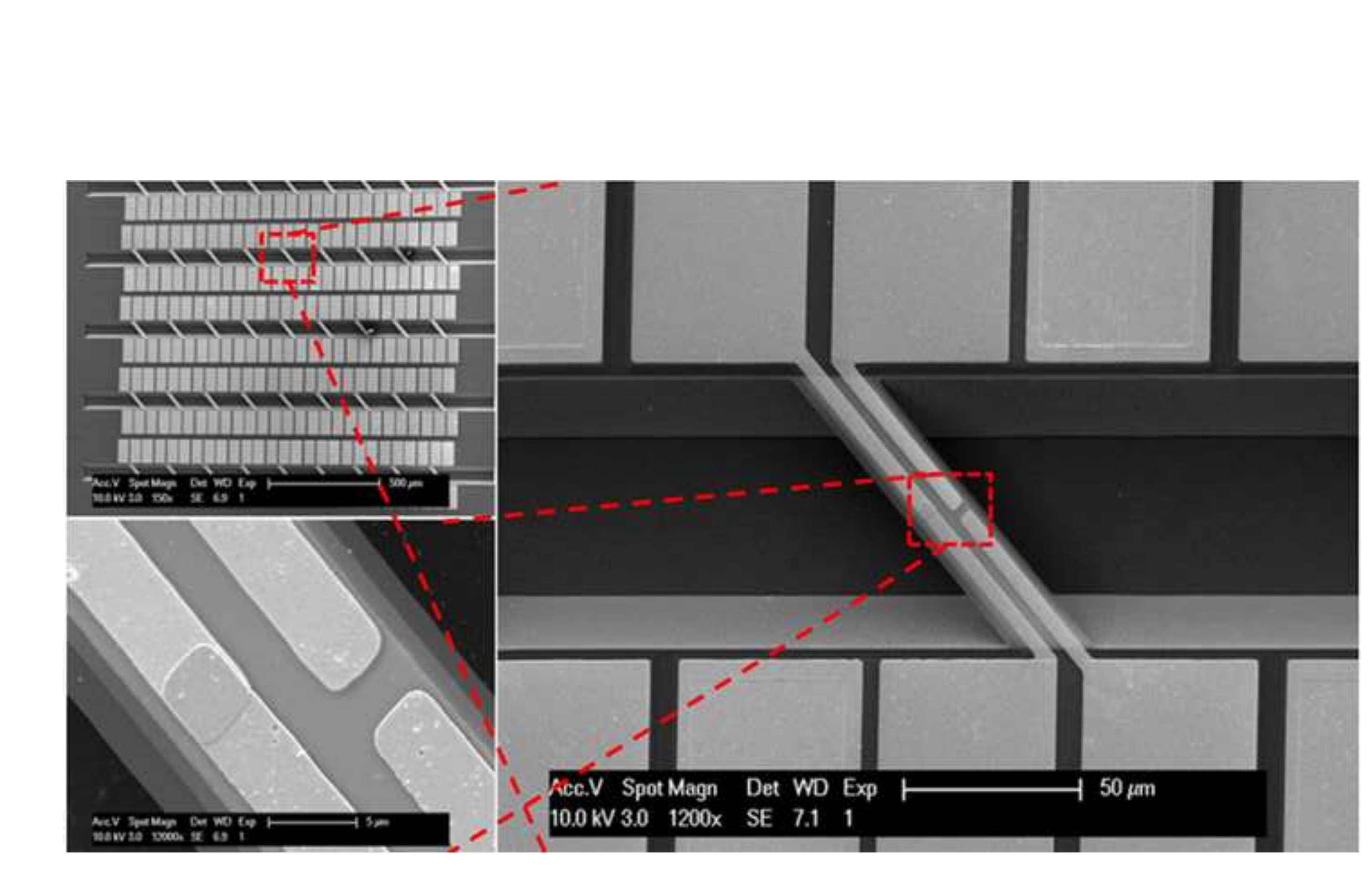

mawn soon 45 is is $10.0 \mathrm{kV} 3.0 \quad 1200 \mathrm{x}$ SE 7.11

\author{
(
}

.
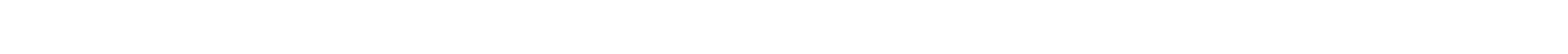

pe 
device glowing at $8.7 \mathrm{~V}$ (estimated temperature 950C)
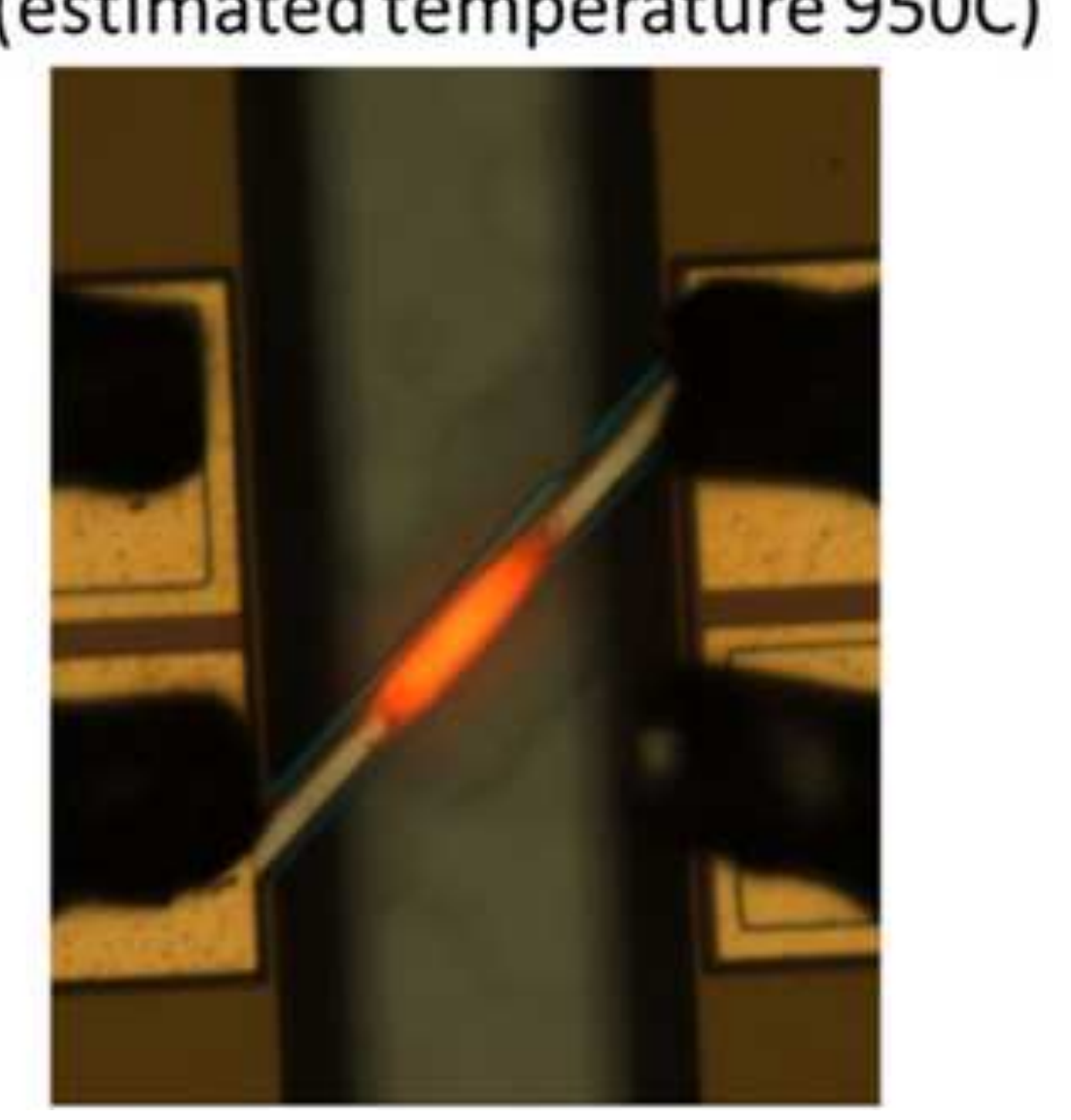

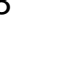

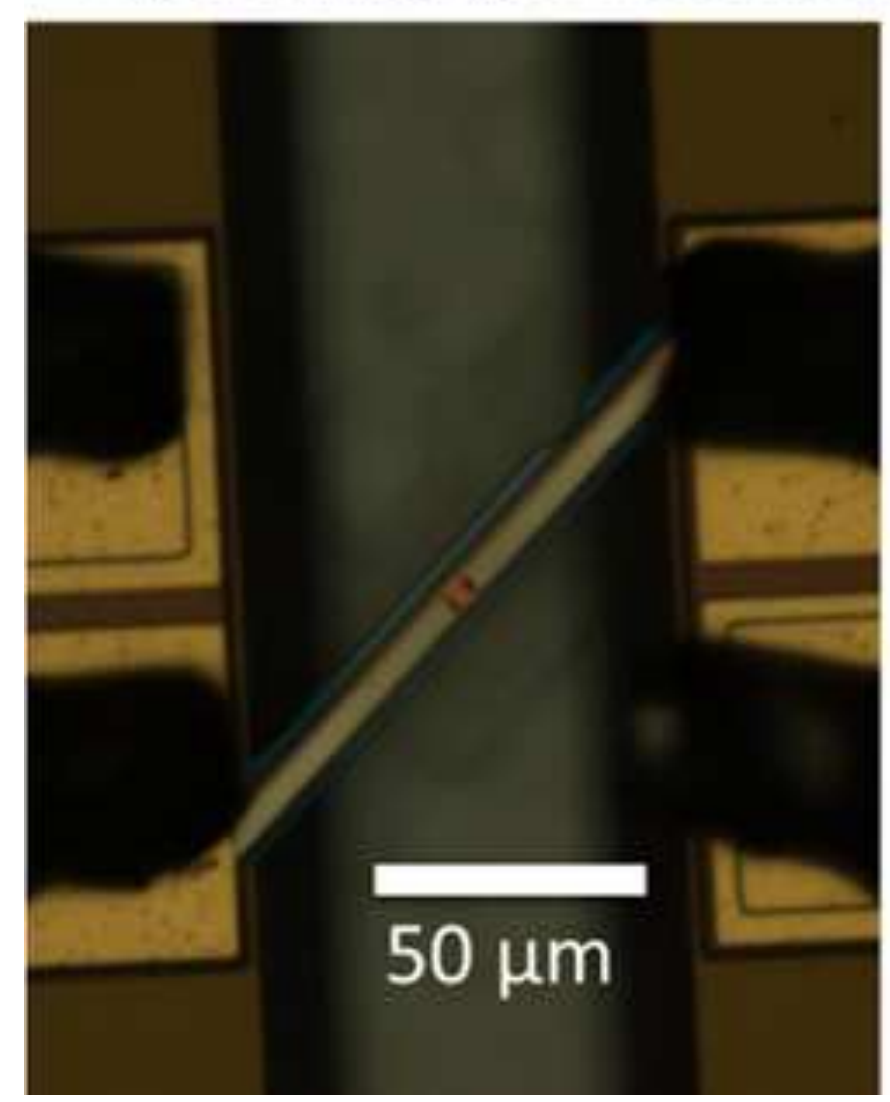

\section{optical image of device}
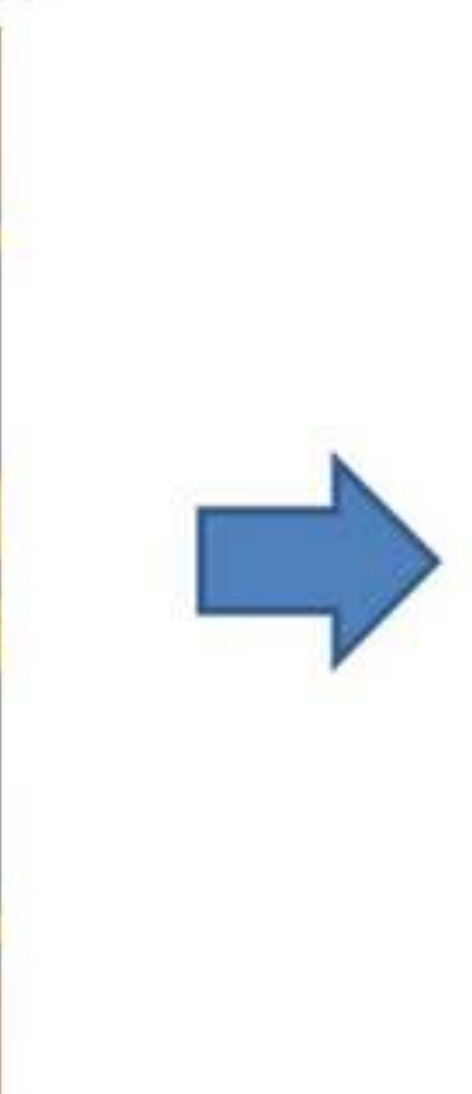
(a) 80

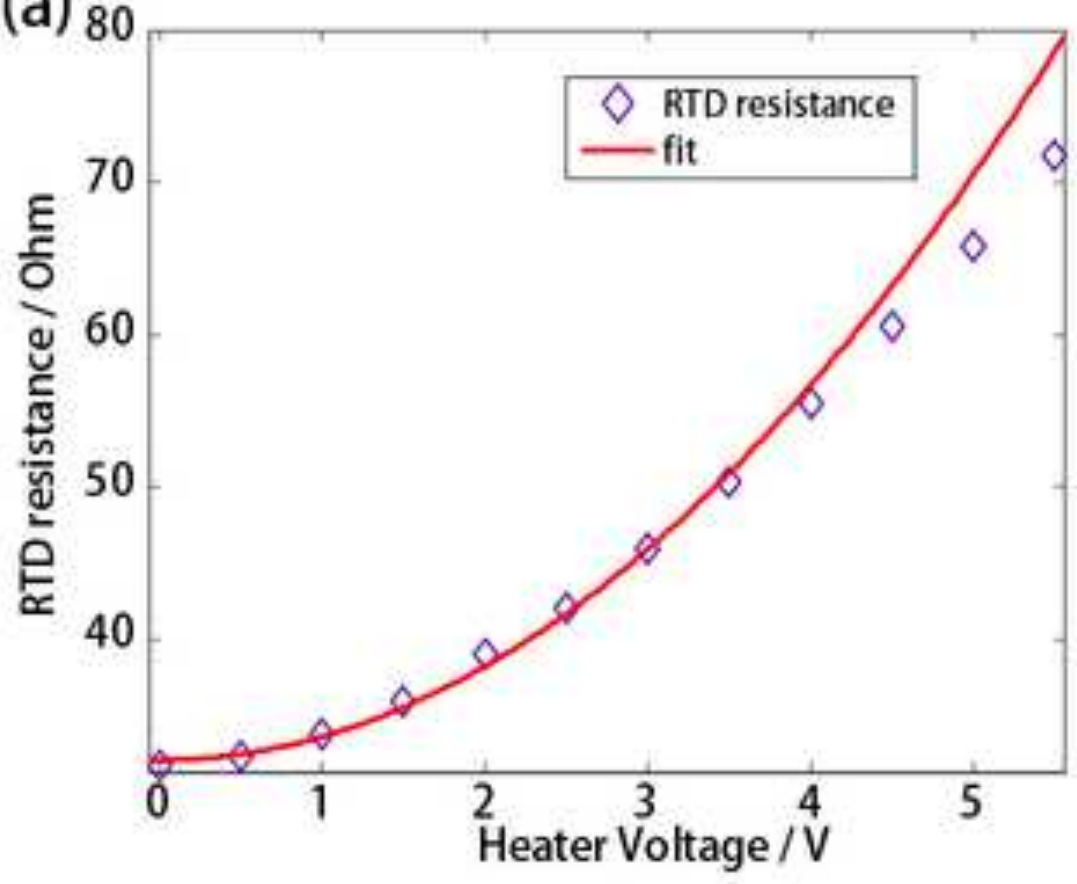

(b)

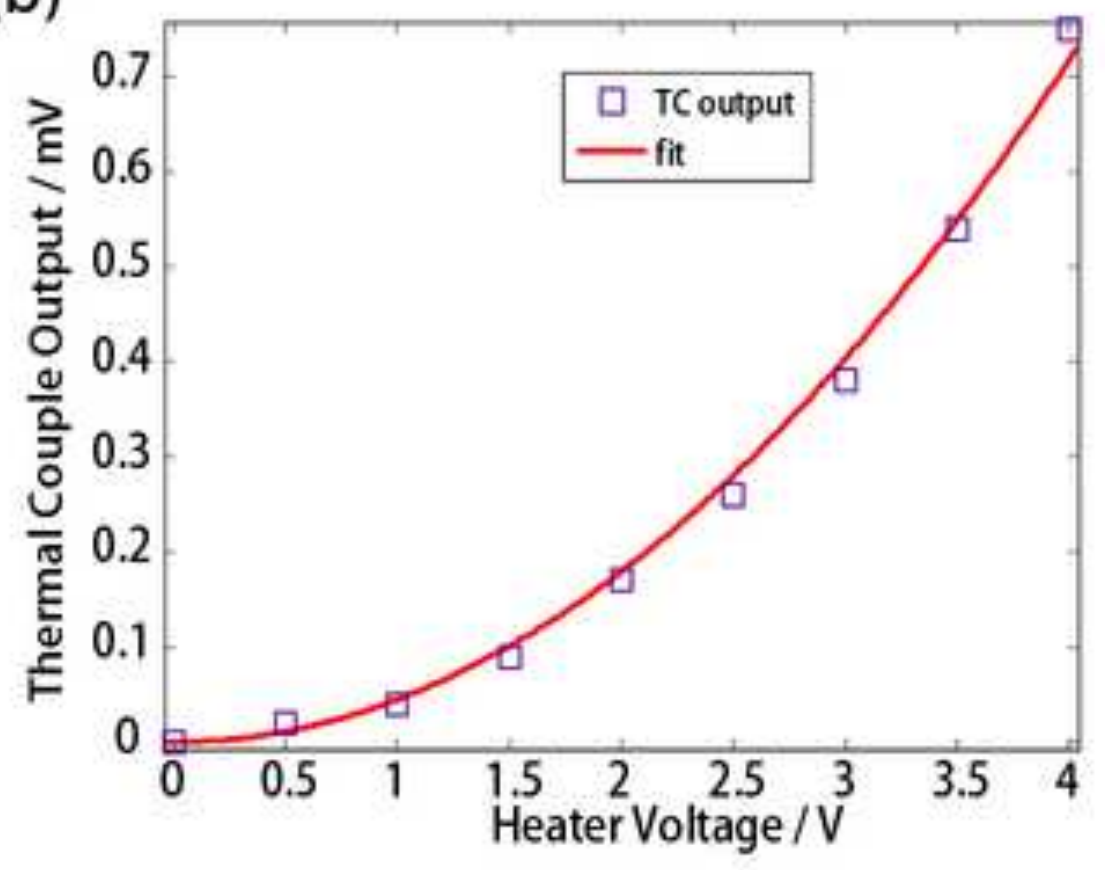


(a)

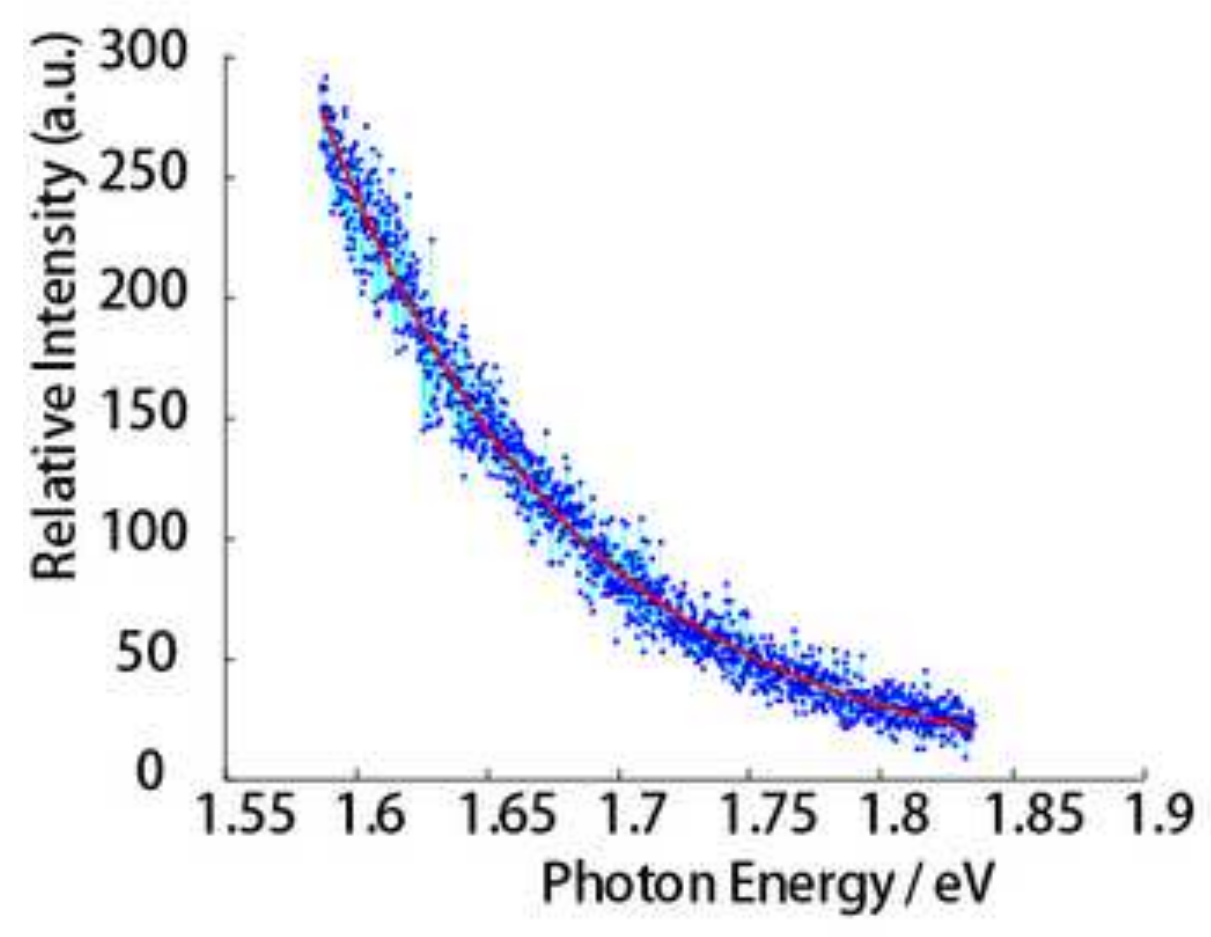

(b)

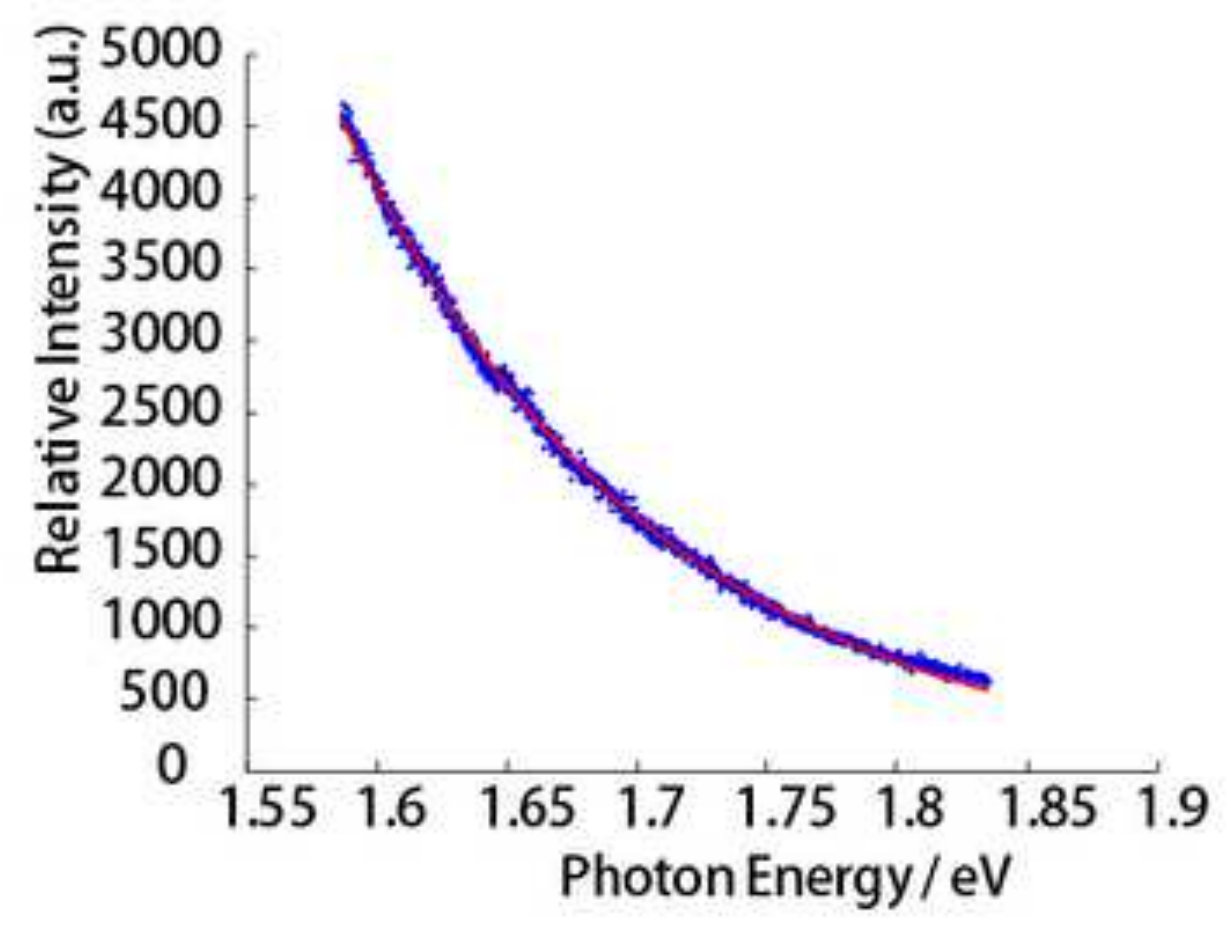


(a)

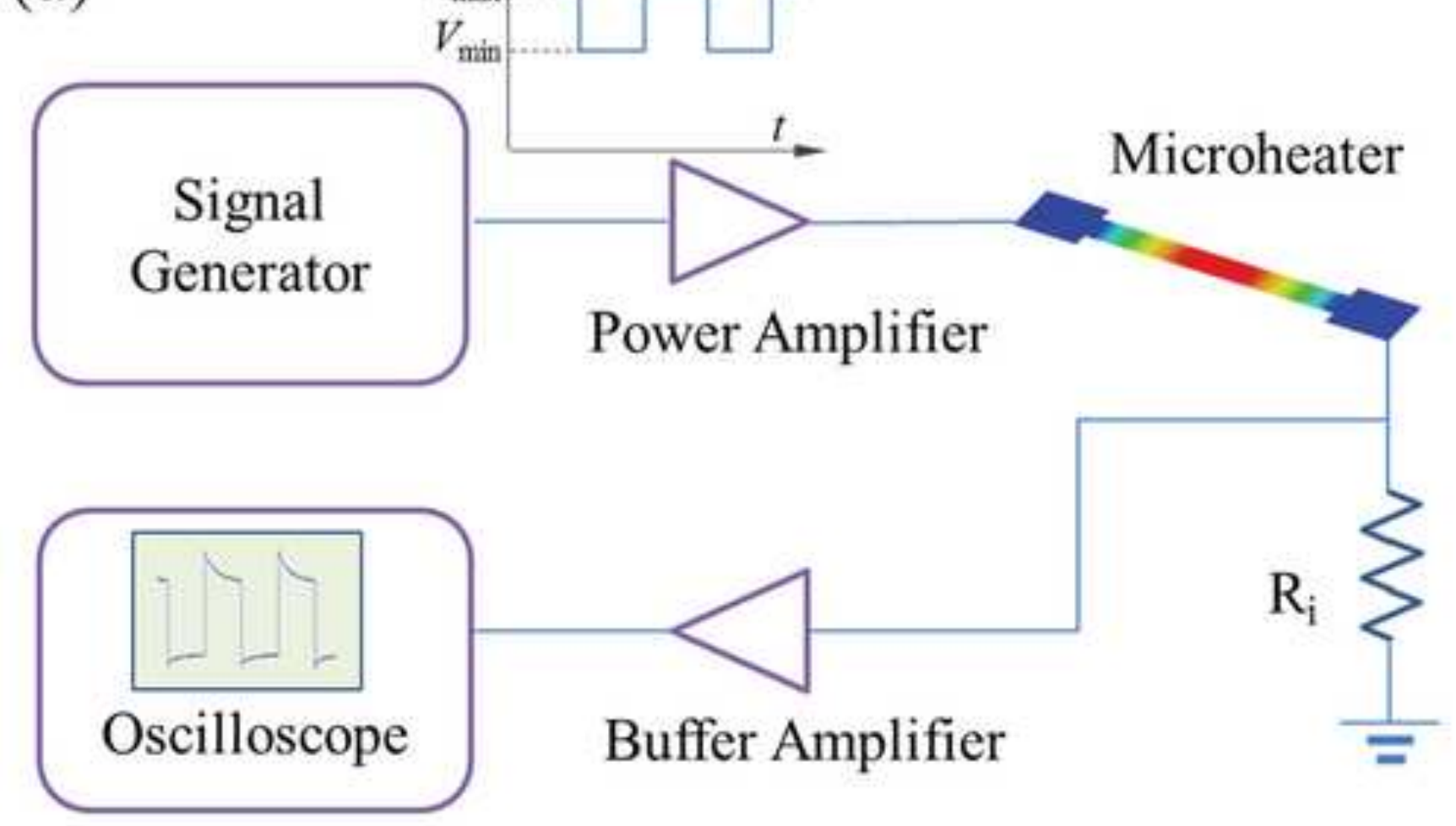

(b)

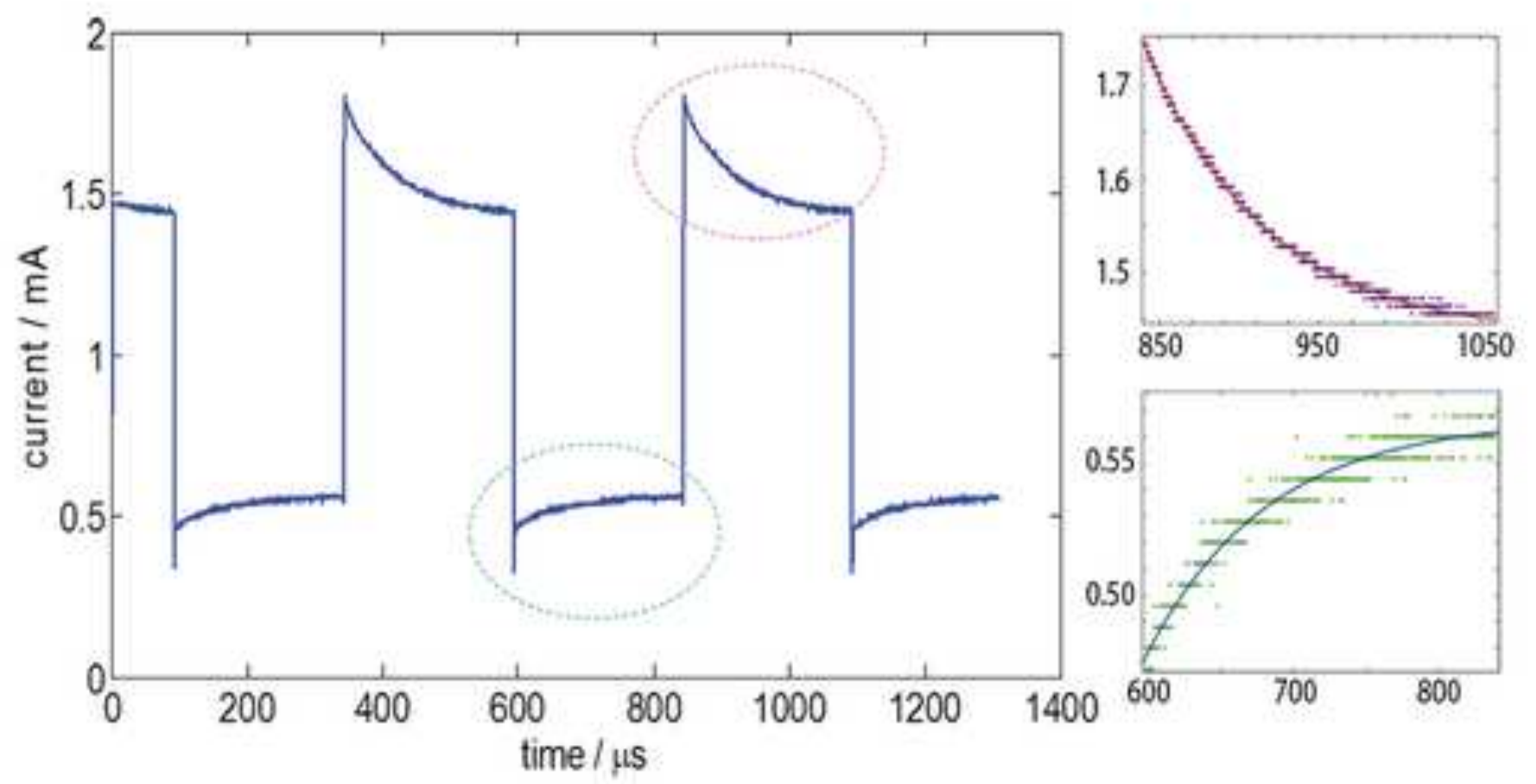



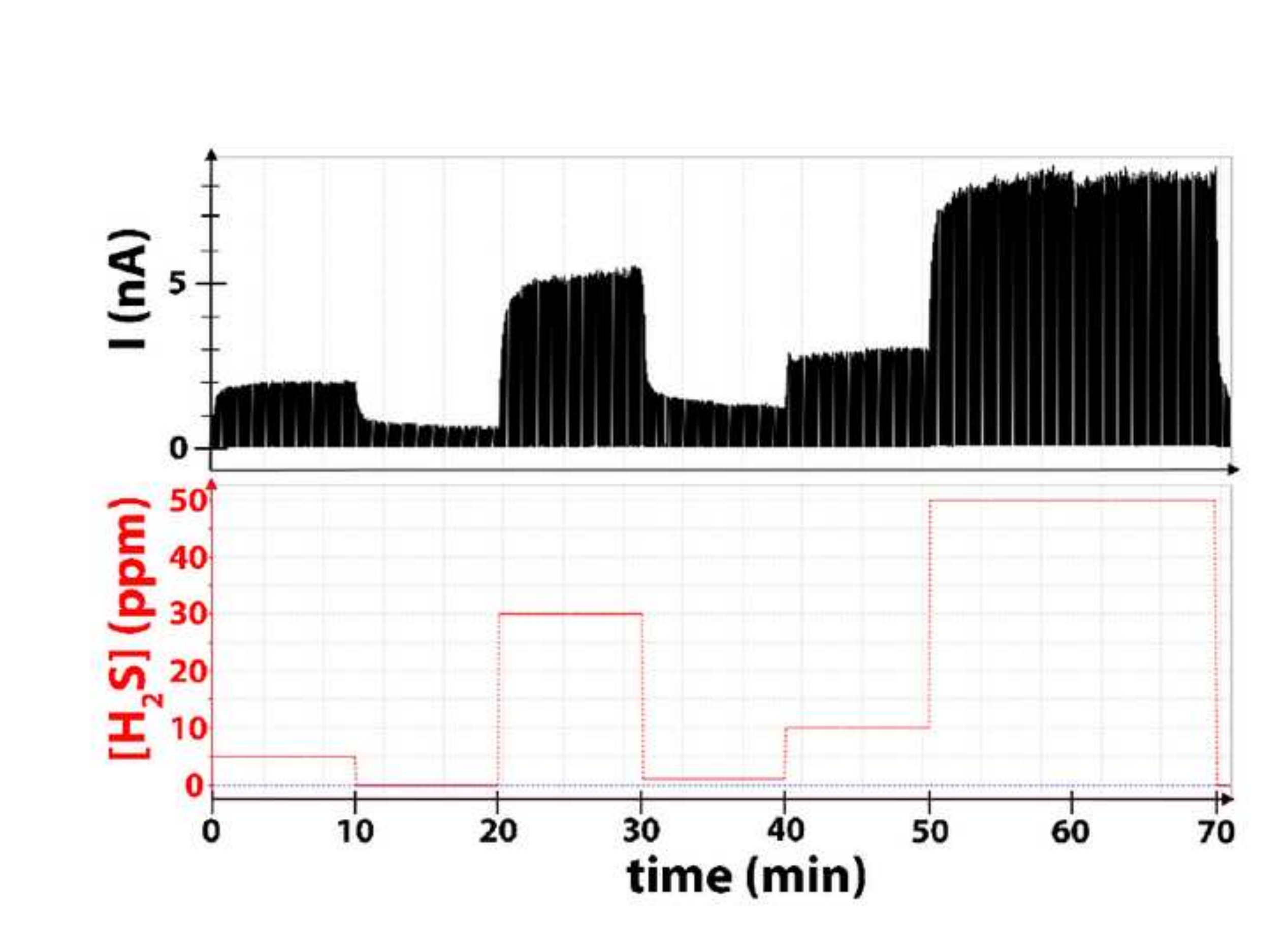

(n)

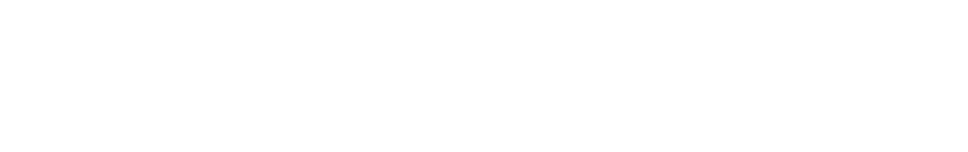

$+2$

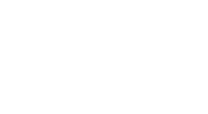


(a)

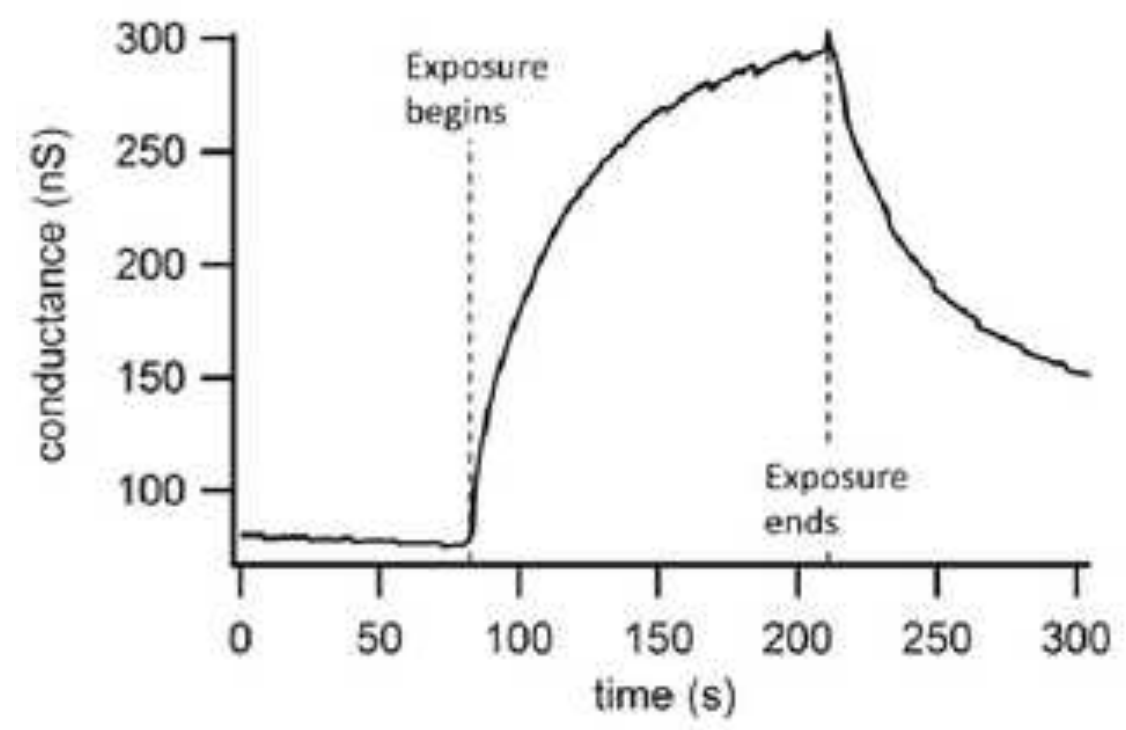

(b)

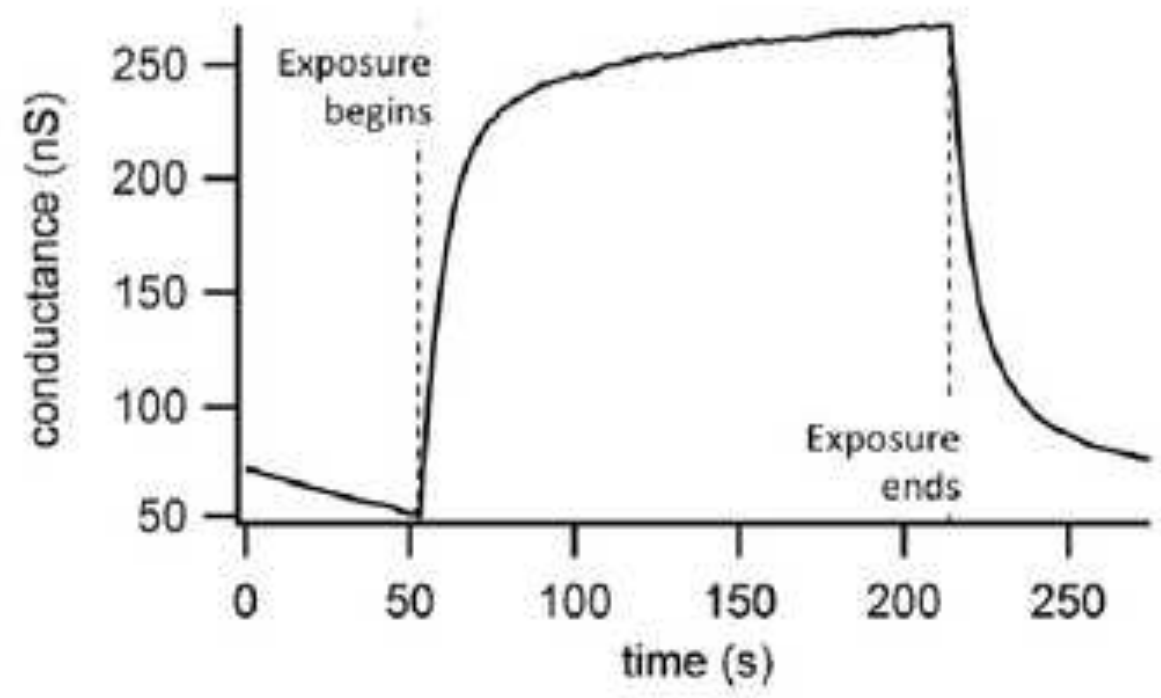


Figure Captions:

Figure 1. Design concept of the suspended microheater.

Figure 2. Power required to reach $300^{\circ} \mathrm{C}$ versus microheater beam length.

Figure 3. (a) Temperature distribution along the length of the beam; (b) Temperature profile of the air around the beam, as determined by ANSYS simulation.

Figure 4. A typical microheater sensor design. (a) Top view. (b) Cross section view of dotted line in (a).

Figure 5. Microheater fabrication process. Color code: Silicon (blue), silicon nitride (green), boron-doped silicon glass (pink), chromium/platinum (brown), and chromium/gold (orange). See text for detailed description of fabrication process.

Figure 6. SEM images of the fabricated microheater array. (Upper Left) Microheater array showing rows of nine microheaters suspended over trenches. (Right) A single microheater device. (Lower Left) Zoom-in on the center of the microheater showing the sensing electrodes with a gap for the sensing layer and a Pt-Au thermocouple junction.

Figure 7. Maximum thermal stability test. Optical images of microheater device with no applied voltage (left) and with $8.7 \mathrm{~V}$ biased across the microheater (right).

Figure 8. Temperature sensor characterization. (a) RTD resistance vs. microheater bias voltage. (b) TC output voltage vs. microheater bias voltage. Red curve is a quadratic fit to the data.

Figure 9. Temperature measured on the microheaters using spectrometer with fittings of Plank distribution. (a) is measured when the radiation from the microheater becomes barely visible to naked eyes, and (b) is measured when the microheater becomes fairly bright.

Figure 10. Transient thermal response of the microheaters. (a) Diagram of the test setup. (b) Measured microheater current. Inset: Data fitted to exponential curves to extract thermal time constants.

Figure 11: Hydrogen Sulfide gas sensing using the new microheated sensors. The upper panel shows the current through a WO3 nanoparticle network operating in "heat pulse" mode (the device is heated for one second every six seconds) while it is exposed to hydrogen sulfide gas. The gas concentration is shown in the lower panel.

Figure 12: Plot of sensor conductance during heat pulse phase versus time while exposed to 50 ppm H $\neg 2 \neg \mathrm{S}$. The heater voltage is pulsed for (a) 1-ms and (b) 100-ms heat pulses every second. 